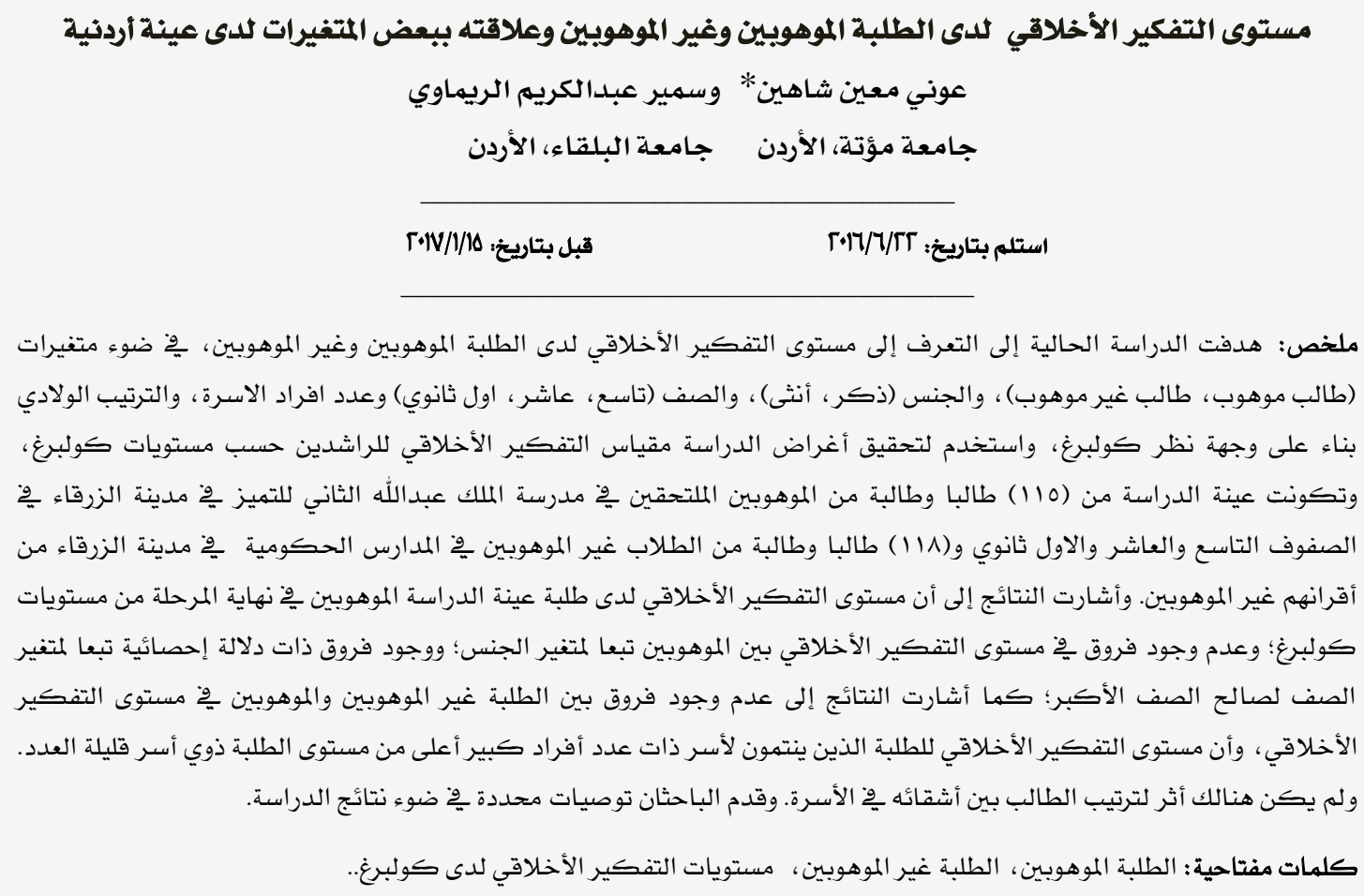

\title{
The Level of Moral Thinking of Gifted Students and its Relation with Some Variables in a Jordanian Sample
}

Awni A. Shahean* \& Sameer A. Al Reamawi

Mutha University, Jordan Balqa Applied University, Jordan

\begin{abstract}
The current study aimed at identifying the level of moral thinking of gifted students in line with Kohlberg aspects. To achieve the study objectives the moral thinking scale was administered a sample of (115) male and female students from king Abdullah II gifted school in Zarqa city. Another sample of (118) normal male and female students in the same classes were included. The results indicated that the moral level of the sample was in the fourth Kohlberg level. No significant differences among gifted students were found due to gender. There were significant differences among gifted student due to class in favor of higher classes. However, there was no significant difference between gifted and normal students in the level of moral thinking. Students who came from families with great number of siblings outscored students who came from families with small number of siblings. Student order of birth had no significant effect on moral thinking. The researchers proposed recommendations based on the results.
\end{abstract}

Keywords: Gifted students, moral thinking levels for Kohlberg.

*awmuin@yahoo.com 
بل بشكل مرحلي متتتابع ومنتتظه، وبصورة

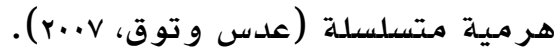

ويعتبر الذكاء الأخلاقي هو القابلية على فهم الصواب من الخطأ. وهو يعني أن تكون

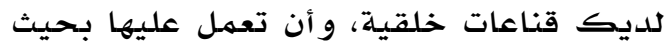
يتسنى لك أن تتصرف بالطريقة الصحيحة

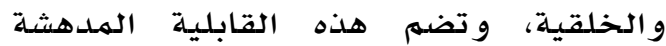

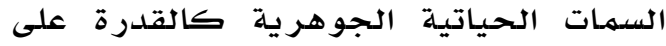
إدرالك الأله لدى أحدهم، وردع النفس عن النوهرئ القيام ببعض النوايا القاسية والسيطرة على السى الهر

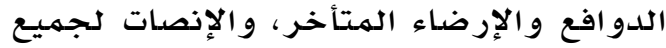
الأطر اف قبل إصدار الحكمه، وقبول الدواء الفروقات ولهات و تقديرها، وتهييز الخيارات غير الخلقية،

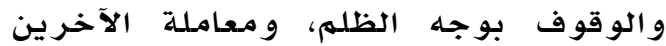
بالحب والاحترام.هذ هي السمات

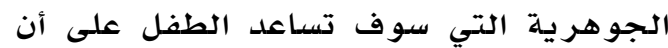

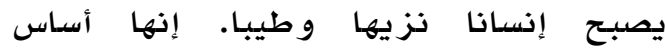
الشخصية المتهماسكة و المواطنة القوية، وهي الأمور التي نود أن نراها لدى أطفالنا بشكل

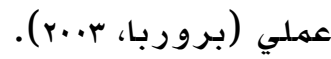

وشغلت قضايا التفكير الأخلاقي أذهان طلبة الفلسفة منذذ عهد أرسطو، وفي علم النفس يلقى التطور في التفكير الأخلاقي اهتماما

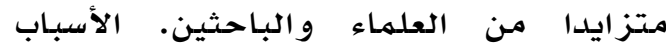
الرئيسلة لتأكيد الاهتمام على هذا البعد

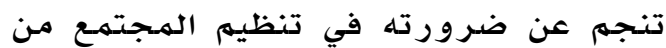
جهة و لعلاقتته بالصراع الذي يعيشه الفرد

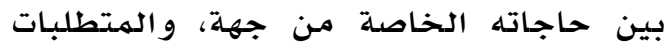
الاجتماعية من جهة أخرى.

و يبحث التطور في التفكير الأخلاقي بكيفية تطوير الأطفال للقيم الخلقية ودراسـة العمليات التي يتهم من خلالها تبني وتذويت التهيت

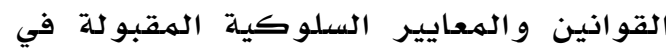
المجتهمع. و التذويت هو تلك العملية التي

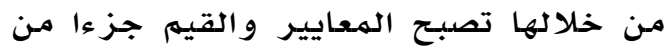

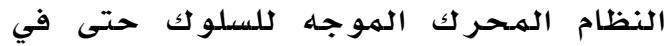
غياب ضغوط الآخرين (الريماوي و آخرون، .) (r.1)
تعد الأخلاق رمز حضارة الأمهم وأسـاس تقدمها وقد حث الإسلام على الأخلاق و اعتبر ها الأساس المكين للدعوة الهـحمدية و الغاية الأسساسية لإسـام، وقال ولهال صلى الله عليه وسلهم "إنما بعثت لأتهمه مكارم الأخلاق"، كما أكدت الكمثير إنها من أدبياتنا و قصائدنا على أهمية الأخلاق في بناء الأمهم.

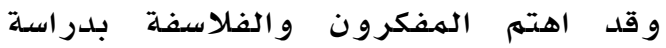

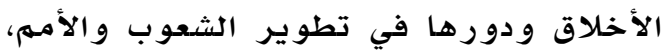
و عندما انفصل علهم النفس عن الفلسفة بدورة الاهتمام التجريبي بالنمو الخلقي والهعايير

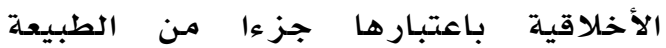

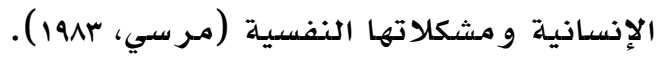
ويلعب التفكير الأخلاقي دورا هاما في الشخصية عن طريق القيه و المثل التي

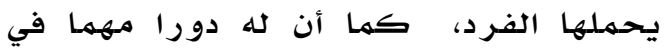
تعريف الصحة النفسية و والسلوك السوي، لهودئ ففي المعيار الاجتماعي يرتبط السلوك

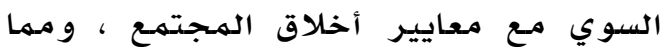
يزيد في أهمية دراسة التفكير الأخلاقي لدى الدى

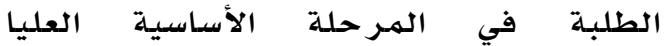
و الثانوية، ما نعانيه اليوم مـن مشكلات تتعلق القيلقيل بالإهمال و والفساد و والتسيب والاستيتلانل والانحر افات السلوكية في المجتمع وشيوع وانهيو الأنماط السلوكية غير السوية كالحسد السد السية و الكر اهية وحب النفس على حسـاب الآخرين، و التي قد تعبر عن أزمة أخلاقية يرجـع

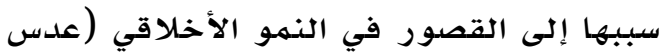

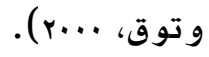

ويرجـع الاهتمام في التفكير الأخلاقي إلى نظرية بياجيه للنمو الخلقي التي طورها في

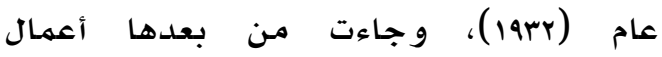

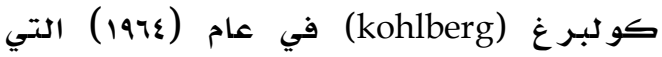
تعد البداية المتميزة علميل في دراسلة التفكير الأخلاقي، حيث طورت مفاهيم بياجيه حول التفكير الأخلاقي، وينطلق

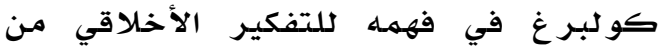
مبدأ أسـاسي بـأن الأخلاق لا تنمو مـرة واحدة 
هو السلوك الذي يبديه الفرد إزاء مـوقف

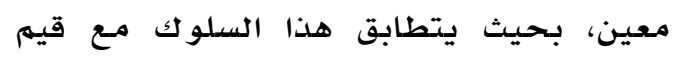

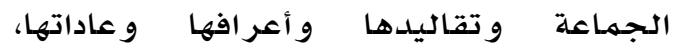

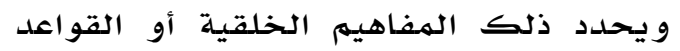

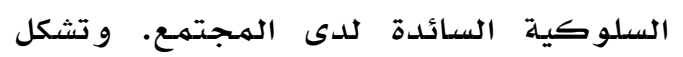

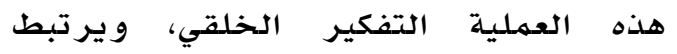

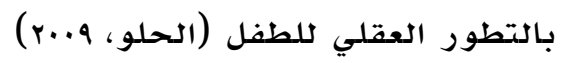

\section{وجهة نظر فرويل والمدرسة الدينامية}

يشير فرويد إلى العلاقة بين الغرائز

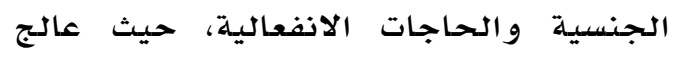

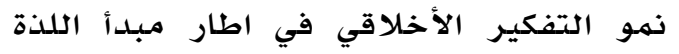
و فكرة الإثم، وأكد على الجوانب التطورية

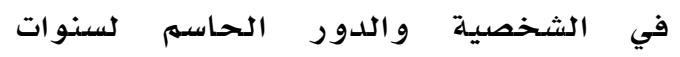

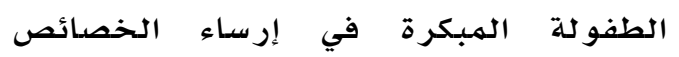

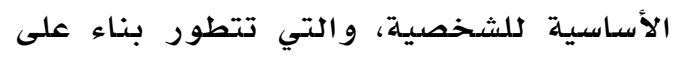

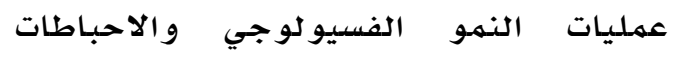

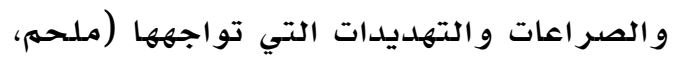
. (r...

ويرجيع الفضل في نقل دراسـة الأخلاق من

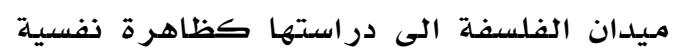

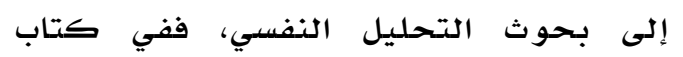

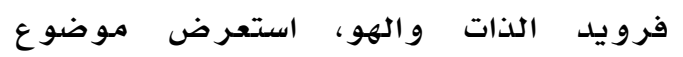

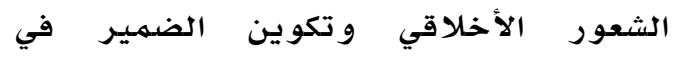

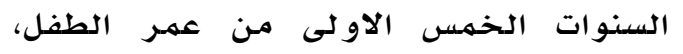

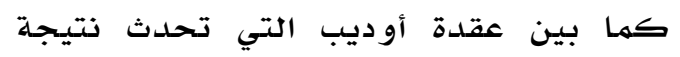

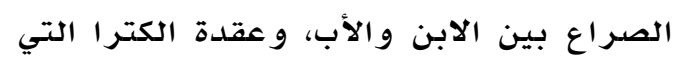
تحدث نتيجة الصراع بين البنت و وأمها. و أكد على أهمية هاتين العقدتين في تطوير

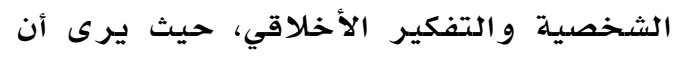

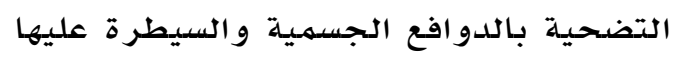

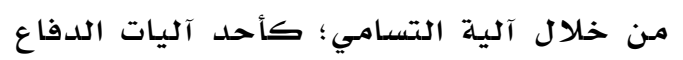

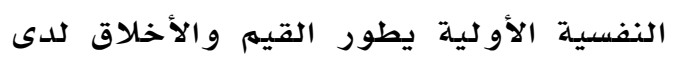

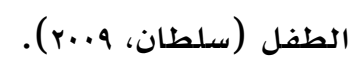

وتتضح وجهة نظر فرويد حول تطور

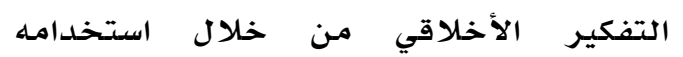

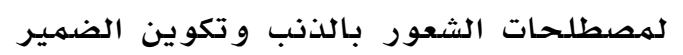

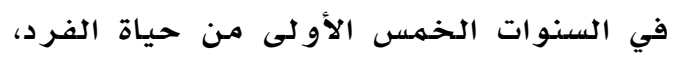
وكذلك تقسيمهـ للنفس إلى ثلاثة أقسام هي: الهو وهي مستودع الغرائز الإنسانية
وتزداد أهمية التفكير الأخلاقي عند التعامل مـع الأطفال الموهوبين، نتيجة النهمو السريع و غير العادي الذي قد يحدث لديهم، مـا لدها يسبب مصدرا للمشاكل العاطفية، ويجعلهم

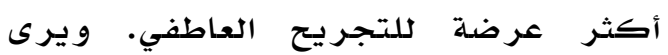
دابروسكي بأن ذلك قد يؤدي الى صراع

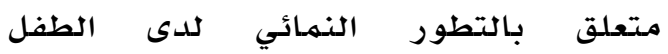
الهموهوب؛ حيث كون نظريته عن النزاهلة الايجابية التي اقترح فيها بأن النمـو المتقديدم يتطلب انهيار بناءات نفسية مدوجودة لتشكيل

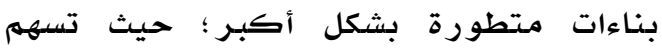

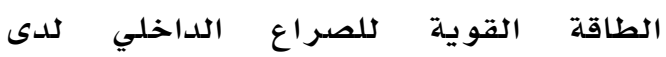
الهموهوبين في نمو وتطور البناءات القيمية (العزة، الهوهودين

تطور مفهوم التفكير الأخلاقي تاريخيا يعرف الغزالي الأخلاق على أنها الهيئة

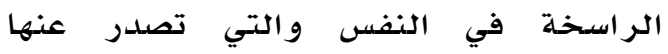
الأفعال بسهولة وومن غير حاجة إلى إعمال

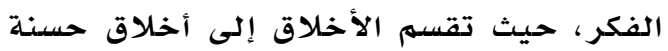

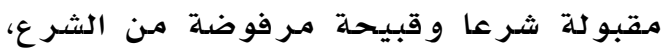

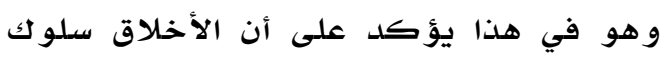
غير متكلف وفعل يقوم بـه الإنسان لسجية راسخة في نفسـه (الغزالي، ع...r). و يعرف الفيلسوف كانت (Kant) الخلق على أنه طبيعة الإرادة، ويرى هادفيلد (Hadfield)

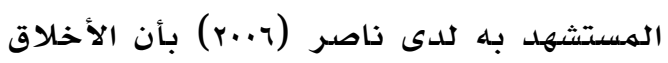
تعبر عن قيمـة النفس المتزنة التي تتوازن فيها الميول الطبيعية و والعواطف وتهن وتهافر

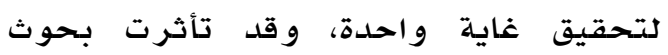
التفكير الأخلاقي بالاتجاهات النفسية و من أبرزها اتجاهات التحليل النفسي والاتجاهات

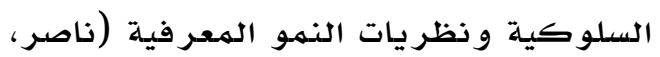
. (r...

و يعد نمو التفكير الخلقي مظهر ا من مظاهر

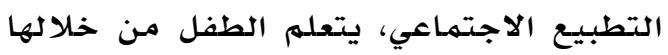

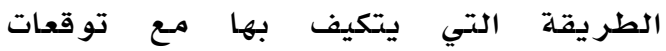

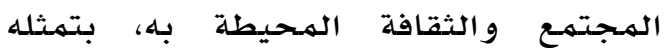

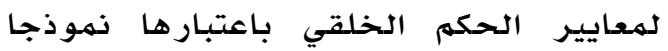

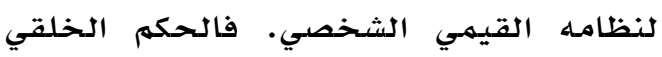


القدرة على اصدار الاحكام الاخلاقية

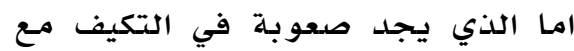
الخبرات الجديدة فيكون أقل اهتماما

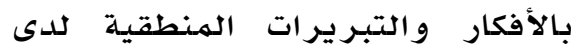
الآخر ين.

التفاعل مـع الأقر ان (Peer interaction)

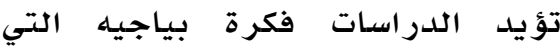
تشير إلى أن التفاعل مـع الأقران يزيد

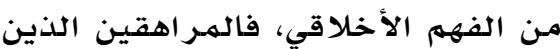
لديهم علاقات حميمسة ويشاركون في الدي النشاطات ويتناقشون مـع الرفاق يتيح المـجال للأطفال للوعي بوجهات نظر الآخرين مها يسهم في تحسين التفكير الأخلاقي لديهم.

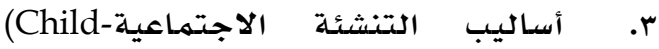
Rearing practices)

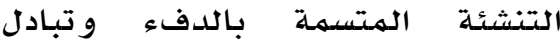
الأفكار بنضج التفكير الأخلاقي لدى الدي الأطفال فالآباء الذين يناقشون ويستخدمون التعليل

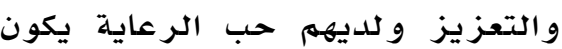

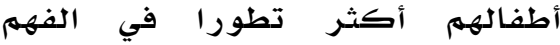

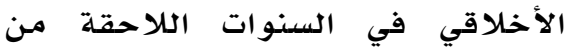
أطفال الآباء الذين يستخدمون التهلديد

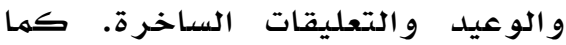
تشير الأبحاث إلى أن الآباء الذين يستخدمون مستويات عالية من الود الودات

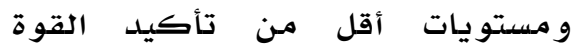
ويشجعون المشاركة في القرارات

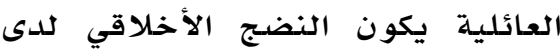
اطفالهم أعلى من غيهم.

التعليه: ويعتبر إتمام سنوات الدراسلة

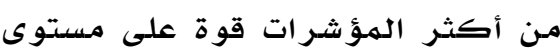
التفكير الأخلاقي، فالتفكير الأخلاقي

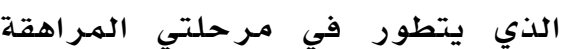
والرشد الهبكر مـرتبط ببقاء الفرد في

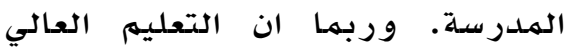
أيضا تأثير ذوعي على النمو الأخلاقي لأنه يعرض الشباب لقضايا تمتد خارج
التي تبحث عن الإثباع المباشر ولا تحتهل التأخير، والثاني الأنا: و هي مجياع الديال الشعور

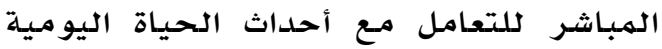
للفرد كما أنها مجال الصراع بين الهراع القسمين الأول و الثالث و هي الأنا الأعلى: مكان القيه

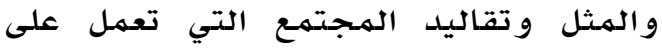

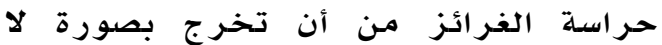
تقرها تلك القيم و والمثل والتقاليد. و محتوى القسهم الأول طبيعي في البناء

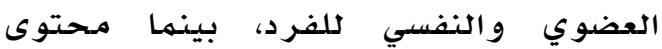
القسم الثالث مفروض على الفرد من قبل مجتمععه من خلال عملية التنشئة الاجتهماعية التي يمر بها خلال مروره بهـراحل النهو الهختلفة؛ وهكذا يكون مكان الأخلاق الأنا الأعلى، وبهذا الهفهوم الفرويدي تصبح الأخلاق مفروضة الهلى على الفرد لا خيار لـه فيها

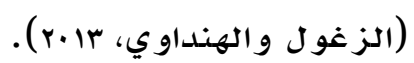

وجهة نظر المدرسة المعرفية: والتي تركز على النمو الهعرفي الإدراكي و عملية اتخهاذ القرار الخلقي الذي يؤدي إلى تطور التفكير

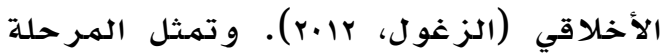

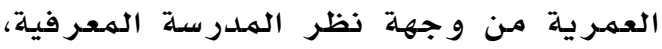

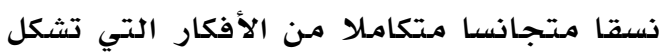
أسـاسـا لإصدار أحكام أخلاقية معينة؛ أي أنها

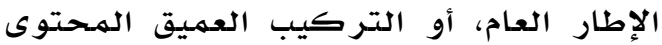
للمسلمات التي تكون وجهة النظر التي يتم على أساسها تحليل الهواقف، ولا يستلزم ذلك معرفة الفرد بهذا الأساس العميق فليس كل فرد قادر على أن يدرك أو يعبر عن المنظور الذي يدفعه لإبداء رأي معين.

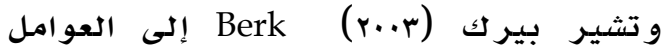
الهؤثرة على التفكير الأخلاقي:

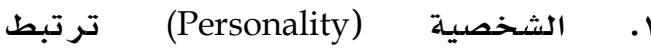

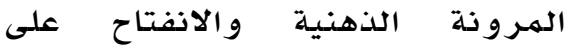
الخبرات الجديدة بتطور التفكير التهير

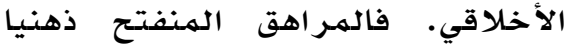
أكثر مشاركة في الحياة الاجتماعية وهذا بالتالي يزيد من تعرضه آلآراء ووجهات نظر مختلفة تمكنه من من 
حيث يعتقدون أن الغرض من الألعاب هو تبادل الحركات بين اللاعبين

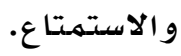

r مرحلة الانصياع للسلطة والتبعية

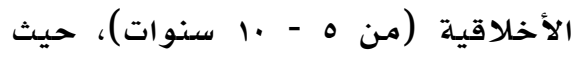
تتميز القواعد بأنها أخلاقية مطلقة الآنة و لكل قضية جانب صح وجانب خطأ، ويقيمون الذنب بناء على النتائج بغض ونانب

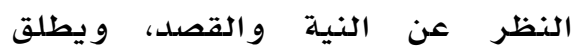

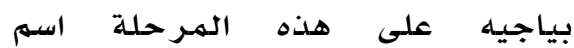
الواقعية الأخلاقية لأن الأطفال ينظرون للقواعد على أنها مظاهر الاند خارجية للواقع و ليس على أنها مبادئ لتنظيم حياة الأفر اد.

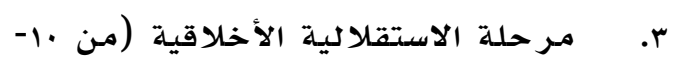

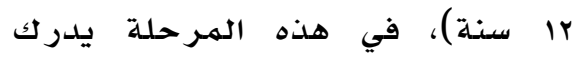

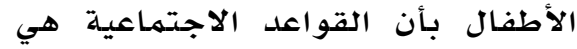
اتفاقيات تم وضعها بطريقة اعتباطية، و يمكن تجاوزها ضمن ظروف معينة

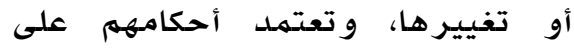
السلوك على النية والقصد و يفضلون العقاب البديل الذي ليعالج نتائج

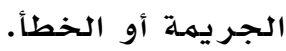

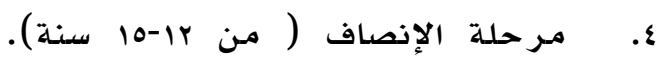

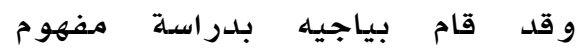
القواعد في الألعاب لدى الأطفال، حيث لداله

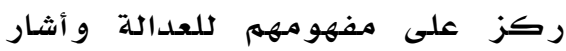

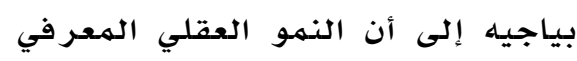

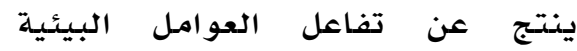
والوراثية ومن وجهة نظره أن دور النيور الوراثة أكبر، حيث يرى أن النه الفرد اندان

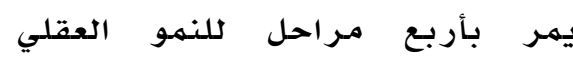
المعرفي في بداية ميلاده إلى مرحلة المراهقة؛ وبعد أن أثبتت الدراسات

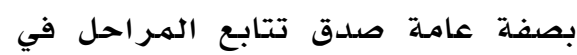

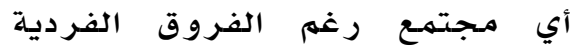

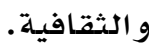

$$
\text { نطاق العماعات السياسية و الثاتية }
$$

ه. الثقافة: تبين الدراسات عبر الثقافية

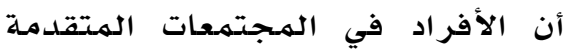

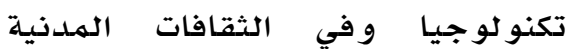
ينتقلون إلى المراحل التي أشـار إليها

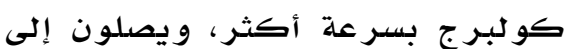

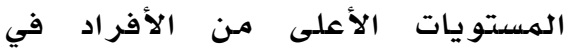
المجتمعات غير الصناعية ووفي البيئات

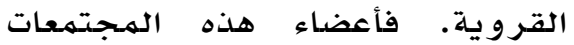

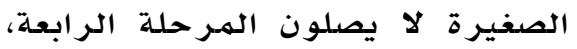
و يمكن تفسير ذلك من خلال فهم

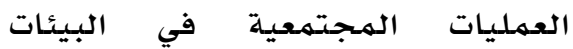
المختلفة، ودور المؤسسات الاجتمهاعية في تطور الفهم الأخلاقي لدى الأفر اد.

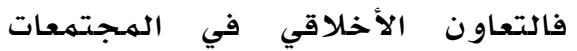
القروية يعتمدد على العلاقة المباشرة المبرة

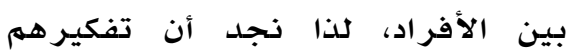

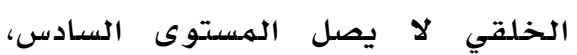

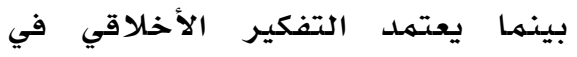

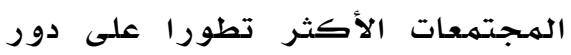

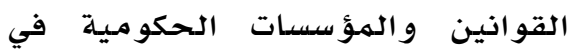
حل النزاعات، وهذا يؤدي إلى الوصوات لهول

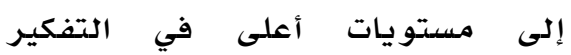

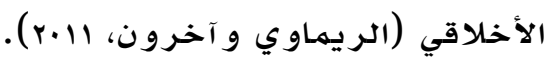

ويشير مفهوم المرحلة عند بياجيه والذي

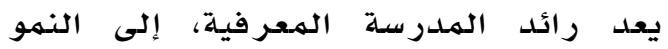

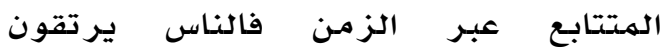
بتحولهم من أخلاقيات التحكم إلى أخلاقيات

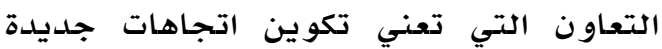

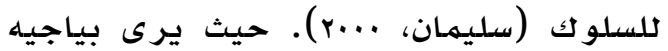
أن هنالك علاقة بين مراحل النهمو المعرفي

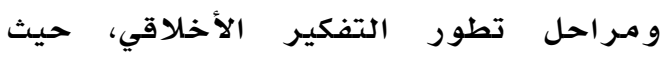

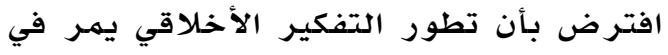

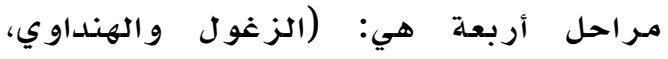
(r.ir ا. مرحلة مـ قبل الأخلاق (من الولادة

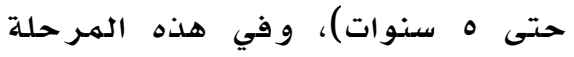

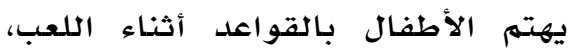


البشرية من ناحية أخرى، وقد صيغت هذه المواقف في صورة قصصية (منسي، .... م).

و تعد الهستويات النظرية التي قدمها كولبرغ في نظريته حول نهو التفكير الأخلاقي من أكثر وجهات النظر قبو لا لدى

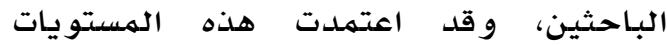

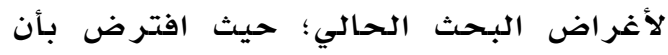
التفكير الأخلاقي ينهو عبر تدرجه في ثلاثة

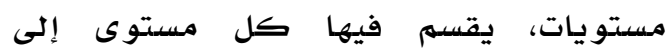
مرحلتين، وفيما يلي لهذئه المستو يات:

المستوى الأول: ويسمى ما قبل العرف أو القانون: حيث تحر كهم دو افعهم ورغباتهم وحاجاتهم دون التر كيز على قيمـة الصواب و الخطأ للسلو ك، وتقسهم إلى مرحلتين هما:

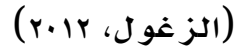

مـرحلة أخلاقية العقاب و الطاعة: يقع غالبية الأطفال تحت سن عشر سنواته في هذه المر حلة كنتيجة لتمر كزهم

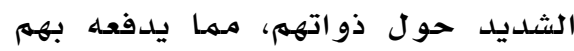
إلى ربط الأحكام الأخلاقية بقول بهواعد

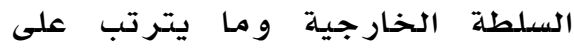

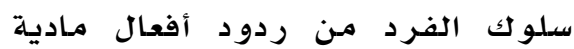

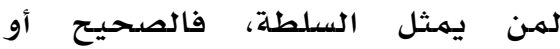
المقبول هو ما تثيب عليه السلطة، و الخطأ أو غير المقبول هو ما ما تعاقب

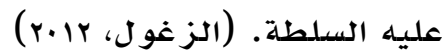
Y. مرحلة الفردية والغائية التبادلية:

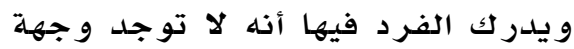
نظر واحد صحيحة تأتيهم من سلطة ولهة ما، ويتم تقييم القرارات الأخلاقية على أساس إثباع الرغبات الشخصية،

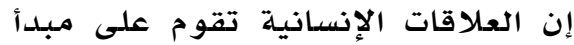

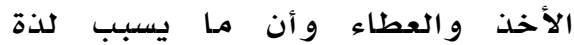
لشخص ما يأتي في المقدمة باءل بالنسبة

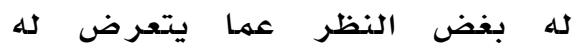

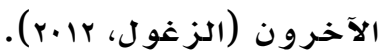

كما يقسهم بياجيه تطور التفكير الأخلاقي إلى ا. الأخلاقية خارجية المنشأ أو أخلاقيات

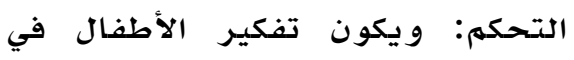

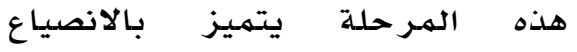
العاطفي للسلطة الخارجية كهما تقوم

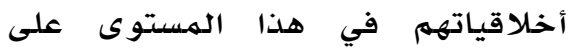

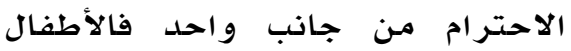

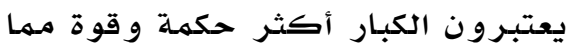
يكون لديهم مشاعر الحب والإعجاب و الخوف وبسبب ذلك تصن تصبح أوامر الكبار و اجبـة التنفيذ.

Y. الأخلاقية الذاتية المنشأ أو أخلاقية

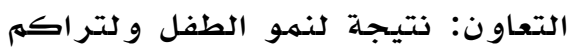

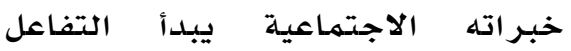

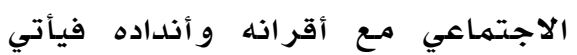
التفاعل على أساس الأخذ و العطاء على أساس تبادلية التأثير والتأثر ولاعلى ويتم إدراك القواعد والترتيبات الاجتماعية عن طريق الخبرة الاجتماعية القائمة

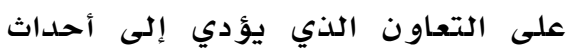

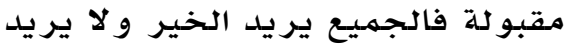
الشر، وبذلك تتضح أهمية التعاون

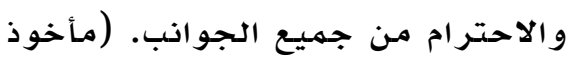

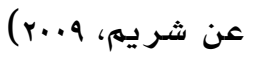

وجهة نظر كولبرغ

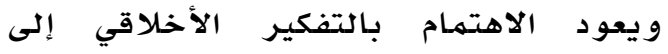

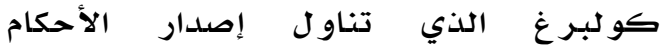
الأخلاقية في رسالته للدكتوراه التي تقدم بها إلى جامعة ثيكاغو عام (1901)، و فيها حدد محككات التفكير الأخلاقي التي استمدها من بياجيه و بالدوين وهير ودوركايم و ميد، و في دراسته فحص كو لبرجيه (التفكير

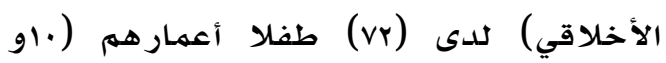

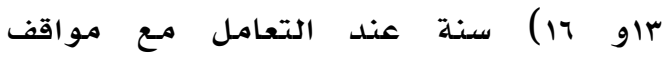

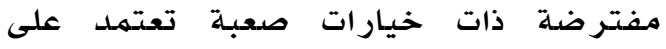
مستويات التفكير الأخلاقي، وفيها صر اع بين

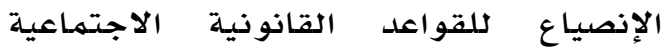
و أوامر السلطة من ناحية، وبين الحاجات 
تكون الأحكام الأخلاقية أكثر تعظيها فيها

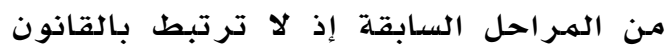
بشكل حر في. و يشمل هذا المستوى مر حلتين هما: (عدس و توق، ب...V) ا. أخلاقية العقد الاجتماعي و الحقوق الفردية: حيث يتخطى الفرد في هذه

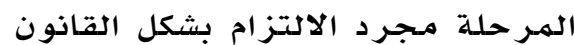
إلى فهم جوهره و أساسـه الذي يعتمد لهد

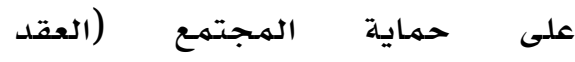
الاجتهاعي).

r. مرحلة المعايير الأخلاقية العالمية

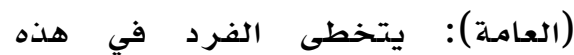
الهـرحلة مناقشة القوانين وصدلاحيتها في مواقف معينة ليصل إلى المبادئ الأخلاقية العامة التي تحكم البشر

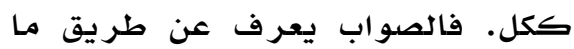
يقرره الضمير طبقا لمبادئ أخلاقية يختارها الشخص لنفسه وتحتكمم إلى الى احسير

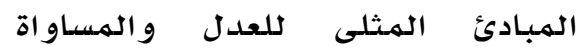
بغر ض تحقيق التوازن بين الحقوق

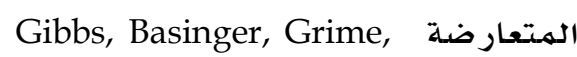

.(\& Snarey, 2007)

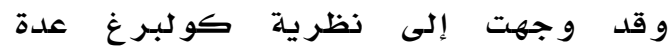

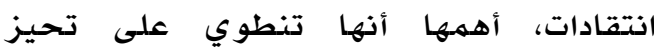
لثقافة الرجل الأبيض و لا تناسب المجتمعات الهُات غير الغربية التي لا يصل فيها الأفراد إلى لى

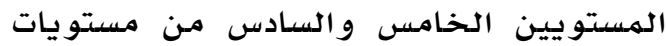
كو لبرغ غ الأخلاقية (Karma-Yoga,2014)،

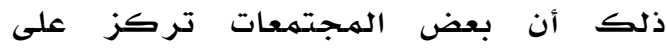

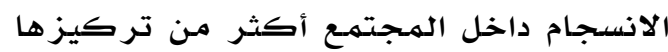
على العدالة والحقوق الفردية للإنسان، كما

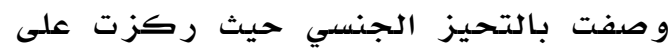
الذكور وتطورهم الأخلاقي، كما أهملت التفكير الأخلاقي لدى الأطفال لصعوبة فهم المشكلات التي طرحها كولبرغ غن من قبلهم

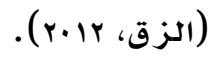

الطلبة الموهوبين

تتعدد التعريفات التي تناولت الطلبة

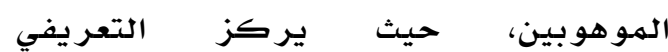

المستوى الثاني: أخلاقيات العرف والقانون: و يعبر هذا المستوى عن تحول كيفي في

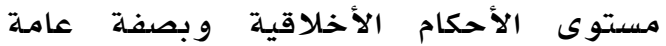
ترتبط أحكام الفرد الأخلاقية بالالتزام

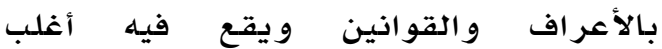
الهـر اهقين و الر اشدين في أي مجتمـع و يشهل

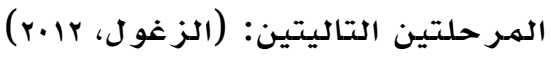

1. مرحلة التوقعات الشخصية المتبادلة

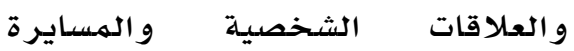

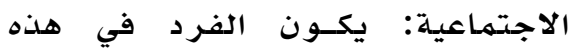
الهـرحلة وجهة نظر فردية في علاقته

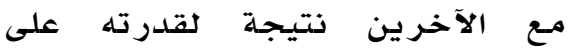
التعرف فعلى المشاعر المتبادلة التي

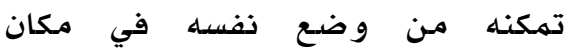
الآخرين واتخاذ القرارات الأخلاقية على أساس عمل ما هو طيب في نظر الناس. ويظهر الفرد القدرة على تفهم

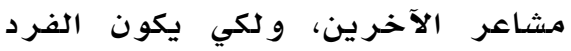

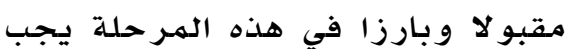
أن تتسهم علاقته بالآخرين بالثقة و الطاعة و الو د. r. مرحلة النظام الاجتماعي و الضمير:

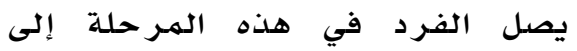
درجة عالية من النهمو الأخلاقي إذ أنه يؤدي الواجبات التي عليه بشكل جيد التهات التهات التهات متجاهلا العلاقات الشخصية و التوقعات التي تعتبر ضرورة في المر احل

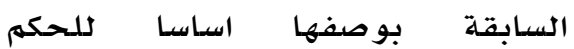

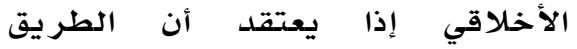

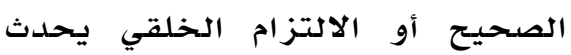

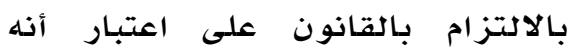
يحمي المجتمـع من السقوط ويمثل القانون مرجعا لحل أي مشكلة حسب الهب رأيه.

المستوى الثالث : ما بعد العرف والقانون: ويصل هذا المستوى كل من المـراهقين

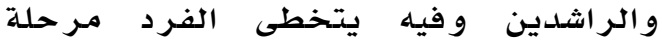

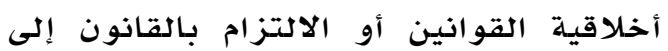

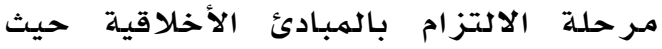


مر تبـة حسب تسلسلها الزمني من الأقدم إلى

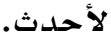

هدفت دراسـة طوقان و أرناؤوط (1910) إلى (تهات

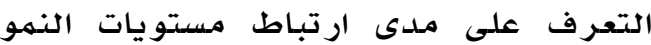

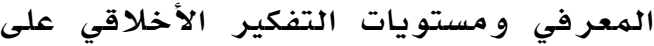

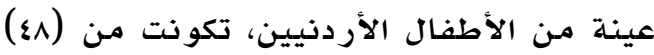
طفلا تم اختيارهم مـن عينة عشوائية تكونت

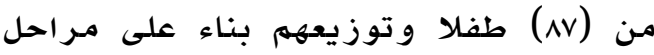

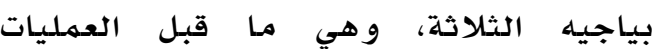
و العمليات المهادية والعمليات المـجردة، بواقع (17) طفلا لكل مرحلة (^ ذهور ور ور إناث)، بواسطة اختبارات شبيهة باختبارات بياجيه، أثارت النتائج إلى وجود علاقة إيجابية ذات دلادة بين مستويات النمو المعر في و مستويات التفكير الأخلاقي.

و هدفت دراسة عباس (1990) إلى الكشف عن تطور التفكير الأخلاقي لدى لالأطفال و علاقته بمتغيرات العمر و والجنس وبيئة التلميذ و الذكاء في عينة مصرية، تكونت

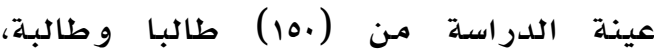
و أثارت النتائج إلى وجود فروق ذات دلادلة إحصائية في التفكير الأخلاقي بين الأعمار

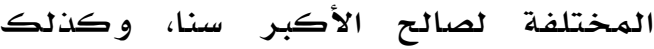
وجود فروق في التفكير الأخلاقي بين أبناء الريف و أبناء الحضر لصالح أبناء الحضري، كما أثـارت النتائج إلى وجواءد الى علاقة ارتباطية إيجابية ذات دلالة بين مستوى الإى

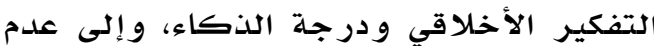
وجود فروق ذات دلالتة إحصائية في مستويات التفكير الأخلاقي بين الذهودر

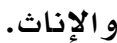

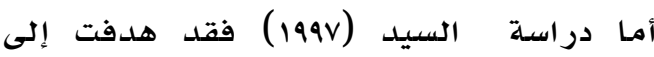
دراسلة العلاقة بين التفكير الأخلاقي ومستوى النمو المعرفي على عينة مصرية من طلبـة الهـرحلة الأساسية تكونت من النهوي (1.0)

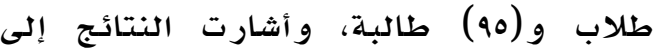
وجود علاقة خطية موجبـة ذات دلالة بين مستوى التفكير الأخلاقي ودرجة الذكاء في كل مرحلة من مـراحل بياجيه المعرفية،
السيكومتري الكلاسيكي على نسبة الذكاء كمعيار أساسي في الحكمم على الهوهوبين، بينما تركز التعريفات الحديثة على أكثر من معيار للحكم على الموهبة، فهي تصف

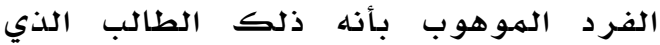
يهتلك استعدادات وقدرات غير عادية تجعل أداءه متميزا عن أقرانه في مجال أو أكثر

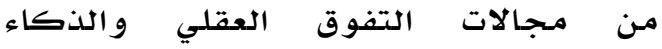
و التحصيل الأكاديهي والإبداع والإن المهارات أو الو القدرات الخاصدة (السرور،،•(r). و قد بلدأت وزارة التربية والتعليم في الاردن الاهتمام بالموهوبين عمليا في التسعينات من القرن المـاضي، حيث افتتحت الهـراكز الريادية للموهوبين ثم تبعها افتتاح مدارس الهمبل الملك عبدالله الثاني للتتميز، والتي يتهم قبول الطلبة فيها وفـق لهـهموعـة مسن المعاييـر الهـحسددة مــن قبـل الــــوزارة علــى النـحــو الآتــــي: ا. أن يكون الطالب أو الطالبة قد أنهى الصف السادس الأساسي. r. أن يكون الطادب ضمن نسبة ه\% مـن الطلبة الحاصلين على أعلى المعدلات في الصف السـادس الأسـاسي. r. ترشيح الملدير والمعلمين والأهل ضهن معايير الترشيح.

ع. السمات والخصائص السلوكية للطلبة.

و يخضــع الطلبــة المـرشحــون مهــن تنطبـقق عليهـهم الشـروط إلـى إختبــار القــدرات

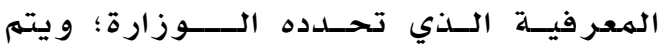
اختيار هم بناء على نتائجهم في هذا الاختبار

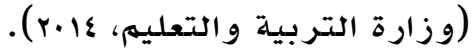

الدراسات السابقة هناك العديد من الدراسـات التي تنـاو لت تطور التفكير الأخلاقي لدى الهوهوبين و غير الهموهوبين، وفيما يلي أكثر هذه

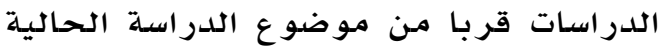


في دراسة أجراها شين يونغ واولوزسكي

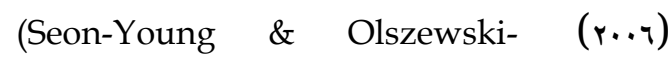

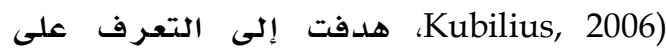
مستوى التفكير الأخلاقي لدى عينة تكونت

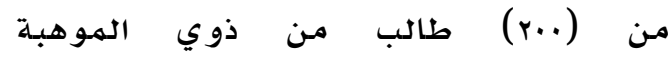

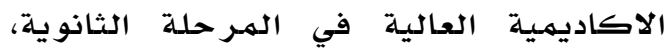

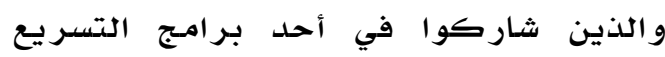

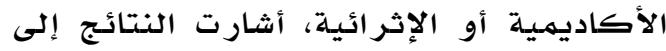

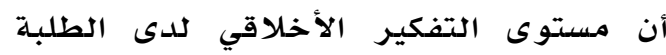

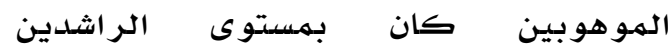
الحاصلين على درجة الماجستير • لمكرين

و في دراسة قام بها لويس (r..v) (r.vis,

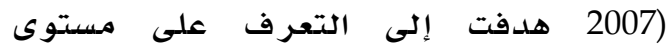
التفكير الأخلاقي لدى الطلبـة الهوهو هوبين؛ و فحص الدلائل البحثية التي تشير الى فه الى

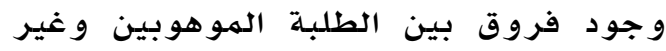

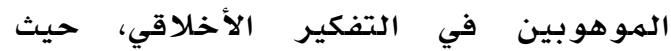
تكونت عينة الدراسـة من (بهو) طالبـا موهوبا

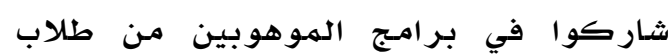
المـرحلة الثاذوية من منطقة الغرب الأوسط لهـ

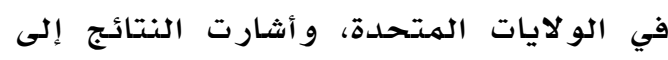
وجود فروق ذات دلالة إحصائية بين الطلبة

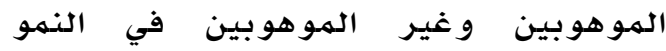
الخلقي لصالح الهوهوبين، كها أشارت الى الى عدم وجود فروق بين الطلبة الهوهوبين في

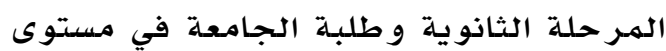
التفكير الأخلاقي.

و هدفت دراسلة مشرف (r..q) إلى التعرف على مستوى التفكير الأخلاقي و وعلاقته ببعض العوامل لدى عينـة مـن طلبـة جامعة آنس

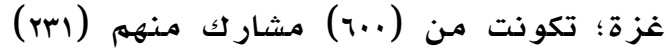

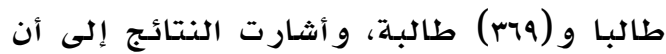

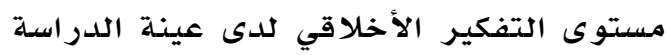
يقع في المـرحلة الر ابعة مـن مـراحل التفكير الأخلاقي.

أما دراسـة تيري (Tirri, 2011) (r) فهدفت

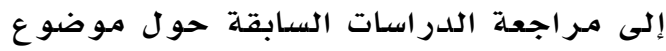

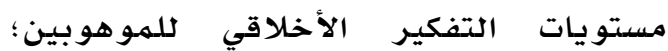
و أكدت معظم الدراسات بأن مستوى التفكير
كما أشارت إلى وجود فروق في مستوى

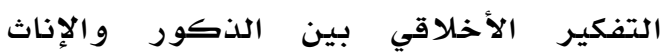
لصالح الإناث.

هدفت دراسة آدم (Y..r) إلى كشف العلاقة بين مستوى التفكير الأخلاقي والتحصيل الدراسي والهستوى الاجتهماعي الاقتصادي لكلأسرة لدى طلبـة الصف الأول الثانوي في

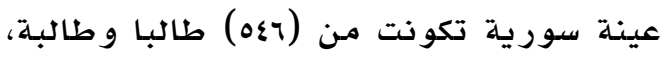
و أشارت النتائج إلى وجود علاقة إيجابية بين التفكير الأخلاقي و متغير ات التحون التحصيل الدراسي والمستتوى الاجتماعي الاقتصادي

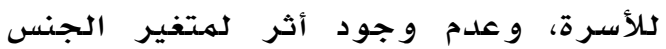
على مستوى التفكير الأخلاقي.

و في دراسـة قام بها دريبري، ويلسون،

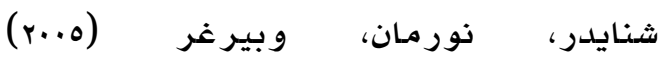
(Derryberry, Wilson, Snyder, Norman \& هدفت إلى التعرف Barger, 2005) الفروق في مستويات التفكير الأخلاقي بين

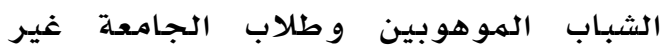

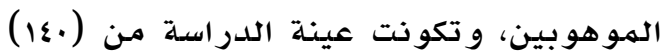

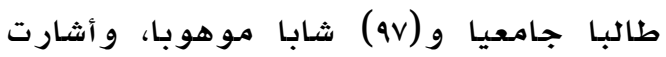
النتائج إلى عدم وجود فروق بين الذكور و الإناث الهوهوبين في التفكير الأخلاقي؛ و إلى وجود فروق ذات دلالة إحصائية تشير الى تقدم مستوى التفكير الأخلاقي لدى لدى الموهوبين مقار نة بغير الموهوبين.

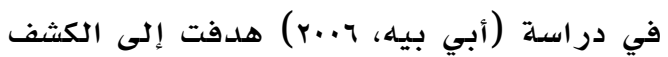
عن مستوى التفكير الأخلاقي والتعرف على التى

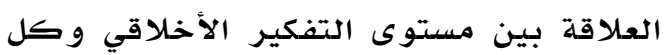

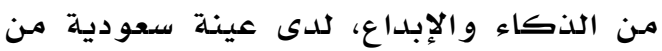

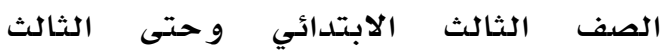
المتوسط تكونت من (rar) طالبـا، و أشارت النتائج إلى وجود أثر دال إحصائيا لهتغير ات

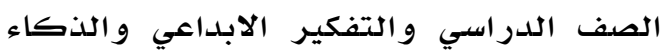
على مستوى التفكير الأخلاقي لصالح الصف

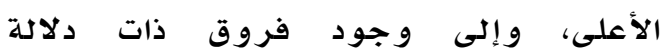

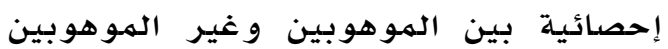
في التفكير الأخلاقي لصالح الموهوبين. 


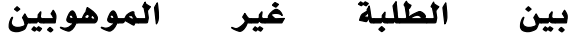

و المو هوبينء

0. هل توجد فروق ذات دلالة إحصائية

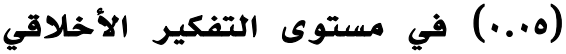
للى الطلبة الموهوبين يعزى لمتغير

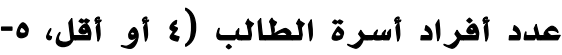

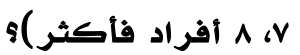

T. هل توجد فروق ذات دلالة إحصائية (.0..) في مستوى التفكير الأخلاقي للى الطلبة الموهوبين يعزى لمتغير

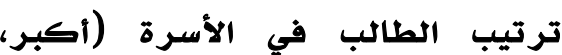
أصغر، أوسط)

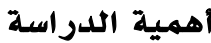

تلقي الدراسـة الحالية الضوء على الجانب

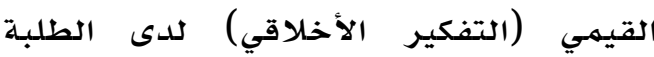
الهموهوبين في صفوف التاسـع والعاشر

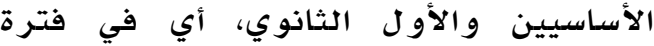

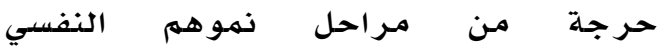
والاجتماعي، وهي فترة المر اهقة التي تتطور فيها الهوية وومفهوم الذات، وتتناول

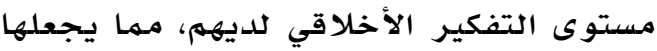
دراسة مهمة انطلاقا من كونها تتناول موضدوعا اجتمهاعيا يمس حياة الفرد وتقدم المهتهـع، كها أذها تلقي الضوء على مستوى

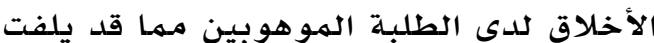
نظر المـربين إلى ضرورة تبني مناهج إرشادية و تعليهية خاصدة لتتنمية الأخلاق لدى هذه الفئة التي يعتمد عليها تقدم

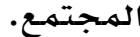

حدود ومحددات الدراسة

تتحدد قدرتنا على تعميهم نتائج هذه الدراسـة في ضوء الحدود و المححددات التالية: الحدود الزمانية: حيث تم تطبيق الدراسـة

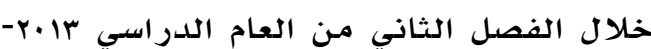
$. r+1 \varepsilon$

الحلدود المكانية: حيث تمثلت بمدينة الزرقاء في الهملكة الاردنية الهاشمية.
الأخلاقي للى الطلبة الهموهوبين أكبر من مستوى أقر انهم غير الهـوهوبين، حيث يثير تيري تساؤلا

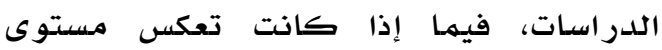
التفكير الهنطقي الأخلاقي لدى الهوهوبين أكثر مهما تعكس مستوى تفكيرهم الأخلاقي

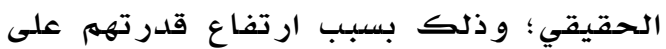
اختيار الاستجابات الصحيحة في اختبـارات

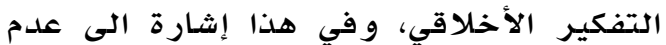
قدرة هذه الاختبارات على قياس التفكير

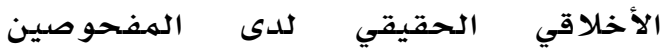

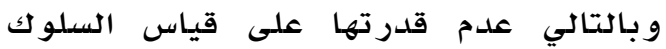
الأخلاقي الحقيقي للفرد؛ و وانما تقيس القدرة على تمييز مستوى التفكير الأخلاقي الأعلى، حيث يوصي تيري بإعادة النظر بهذه الأبحاث و نتائجها. مشكلة الدراسة و أسئلتها

يمكن بلورة مشكلة الدراسـة من كونها

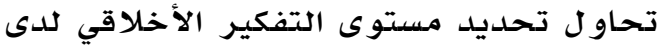
الطلبـة الموهوبين وغير الموهوبين وعلاقته

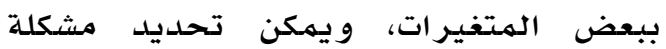
الدراسلة الحالية مـن خلال الأسئلة التالية: 1. ما مستوى التفكير الأخلاقي للى الطلبة الموهوبين الملتحقين في مدرسة الملك عبدالله الثاني للتميز المليه ولدى الطلبة فير الموهوبين في مديرية التربية والتعليم لمنطقة

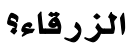

r. هل توجد فروق ذات دلالة إحصائية (.0..) في مستوى التفكير الأخلاقي للى الطلبة الموهوبين يعزى لمتغير

$$
\text { الجنس (ذكر، أنثى)ء الهو }
$$

r. هل توجد فروق ذات دلالة إحصائية (0...) في مستوى التفكير الأخلاقي للى الطلبة الموهوبين يعزى لمتغير

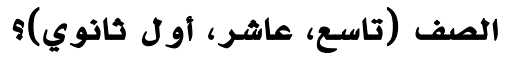
ع. هل توجد فروق ذات دلالة إحصائية

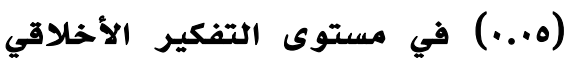




$$
\begin{aligned}
& \text { بيانات مجتهـع الدراسة وتوزيعه على }
\end{aligned}
$$

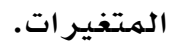

$$
\begin{aligned}
& \text { جدول } 1 \\
& \text { توزيع طلبة مجتمع الاراسة غير الموهوبين حسب }
\end{aligned}
$$

\begin{tabular}{|c|c|c|c|}
\hline \multicolumn{4}{|c|}{ متفير الصف والجنس } \\
\hline المجموع & 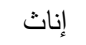 & ذكور & الصف \\
\hline$\Lambda \cdot \leqslant 0$ & $\leqslant 10$. & r 190 & التاسع الأساسي \\
\hline Voor & r911 & 2 & العانشر الأساسي \\
\hline$V \leqslant \pi$ & $\varepsilon \cdot r r$ & $r \varepsilon \varepsilon$. & الأول ثانوي \\
\hline rT. T. & $\mid r .91$ & 1.979 & المجموع \\
\hline
\end{tabular}

بالإضافة إلى جميع الطلبـة الموهوبين من طلبة الصفوف (التاسع والعاشر الأسـاسيين)

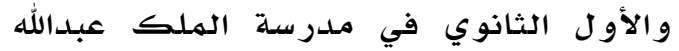

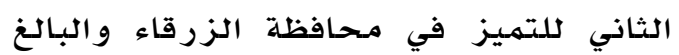

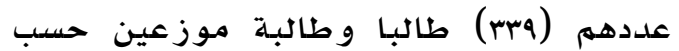

متغير ي الجنس و الصف في جدول r r.

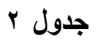

\begin{tabular}{|c|c|c|c|}
\hline \multicolumn{4}{|c|}{ الصف والجنس } \\
\hline المجموع & إناث & ذكور & الصف \\
\hline $10 r$ & V) & NT & التاسع الأساسي \\
\hline 117 & 0 . & 74 & العانشر الأساسي \\
\hline$v \cdot$ & $r$. & o. & الأول ثانوي \\
\hline rqq & $1 \leqslant 1$ & 191 & المجموع \\
\hline
\end{tabular}

توزيع مجتمع الدراسة الموهوبين حسب متفير

عينة الدراسة

تم اختيار عينة عشوائية طبقية من الطلبة

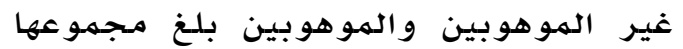

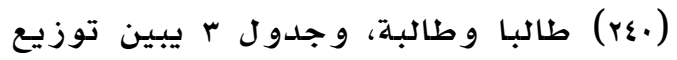

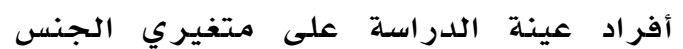
و الصف.

وبعد تطبيق الاختبار عليهم، استثنيت خمسة أوراق لعدم الاكتمال من الطلبـة الموهوبين

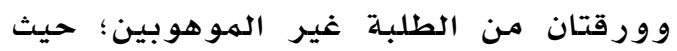

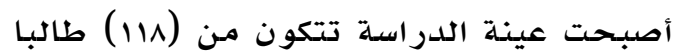

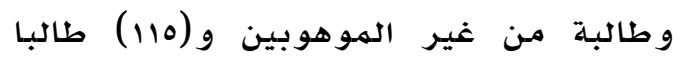
و طالبـة من المـوهوبية.
محلددات عينة اللدراسة: تمثلت لطلبة الصف التاسـع العاشر الأول الثانوي موهوبيه التين وغير

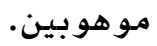

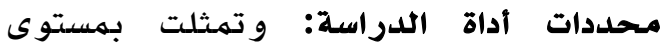
الصدق والثبات لمقياس التفكير الأخلاقي

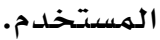
مصطلحات الدراسة التفكير الأخلاقي: ويعرف على أنه مستوى التفكير المستخدم في حل الموقف الأخلاقي أو المشكلة الأخلاقية، وفقا لهـراحل نظرية كولبيرغ الست لتطور التفكير الأخلاقي (عدس وتوق، r..V). و يعرف إجرائيا لغاية

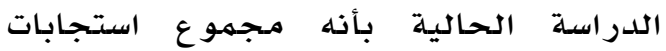

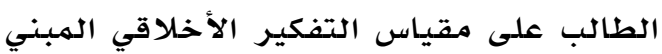

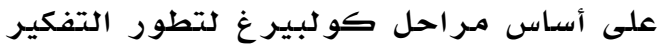
الأخلاقي. الطلبة الموهوبين: هم الطلبـة المصنفين من قبل وزارة التربية والتعليهم الأردنية والذين الذين التهين

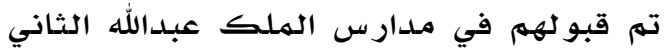
للتميز

الطلبة غير الموهوبين: همر الطلبية

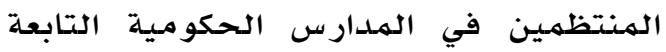

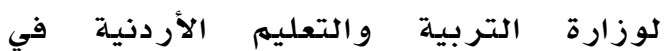
محافظة الزرقاء.

\section{الطريقة والإجر اءات}

\section{منهج الدراسة}

استخدم المنهج الوصفي لتحقيق غايات

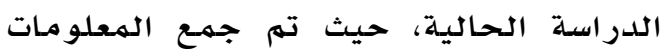
عن عينة الدراسـة بواسطة مقياس التفكير الأخلاقي، و بناء على عدد من الهتيفيرات التي وردت في أسئلة الدراءلة وسلة

مجتمع الدراسة

تكون مجتمع الدراسـة من طلبة الصفوف

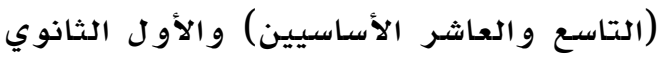
في مدير ية التربية و التعليهم لهنطقة الزرقاء

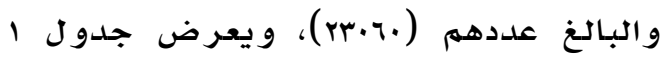




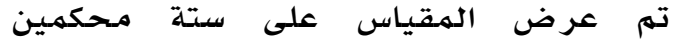

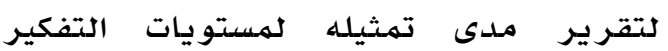
الأخلاقي لدى كو لبرغ و ووضوح عبار اته، حيث تم الاتفاق بينهم على أن المقياس يمثل

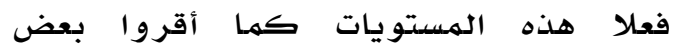
التعديلات للغلة المقياس.

ثبات المقياس: تم استخراج دلالة الثبات للمقياس بطريقة الإعادة، حيث طبق المقياس

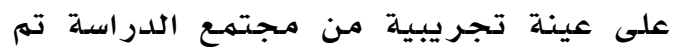

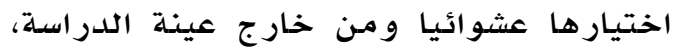

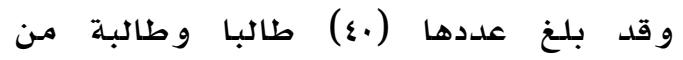

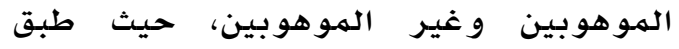

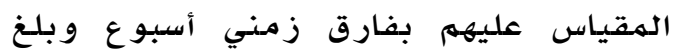

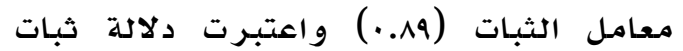
كافية لأغر اض الدر اسـة الحالية.

تفسير النتائج على المقياس: لتحديد المعيار

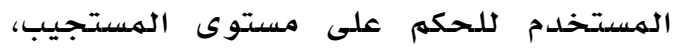
استخدمت الهعادلة التالية: الحد الأعلى - الحد الأدنى للتدرج / عدد المستويات = طول الفئة

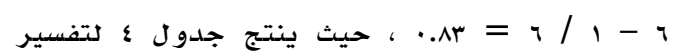
النتائج على المقياس.

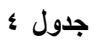
تدرج المعيار المستخدم للحكم على مستويات مقياس التفكير الأخلاقي حسب كولبرج

\begin{tabular}{|c|c|}
\hline الفترة الرقمية المقابلة & مستوى التفكير الأخلاقي حسب \\
\hline I. I... & الأول \\
\hline 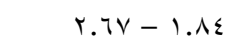 & الثناني \\
\hline$T .01-T .71$ & الثالث الث \\
\hline s.ro-r.or & 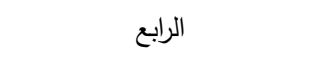 \\
\hline $0.19-\varepsilon . r 4$ & الخامس \\
\hline T... - - . . . & السادس \\
\hline
\end{tabular}

نتائج الدر اسـة و منـاقشتها

لكالإجابة عن السؤال الأول: مأم مستوى التفكير الأخلاقي للدى الطلبة الهوهو الهوبين الملتحقين في مدرسلة الملك عبدالله اللهاني الثاني

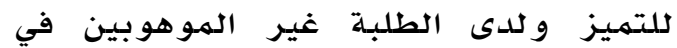

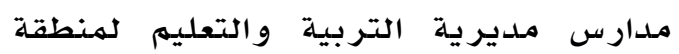

\section{جدول r}

توزيع عينة الدراسة غير الموهوبين والموهوبين حسب متغير الصف والجنس

\begin{tabular}{|c|c|c|c|c|c|}
\hline \multirow[b]{2}{*}{ المجموع } & \multicolumn{2}{|c|}{ إناث } & \multicolumn{2}{|c|}{ ذكور } & \\
\hline & موهوبين & الموهوبين & موهوبين & غير الموهوبيا & \\
\hline$\wedge$. & $r$. & $r$. & $r$. & r. & الأساسع \\
\hline$\wedge$. & $r$. & $r$. & $r$. & r. & الأساسي \\
\hline$\wedge$. & $r$. & $r$. & $r$. & $r$. & ثانوي \\
\hline$r \leq$. & 7. & 7. & 7. & 7. & المجموع \\
\hline
\end{tabular}

أداة الدراسة

تم م استخدام مقياس التفكير الأخلاقي

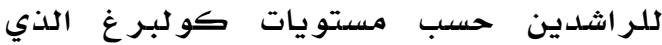

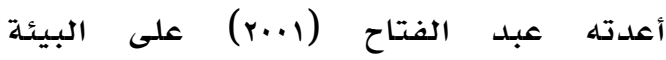

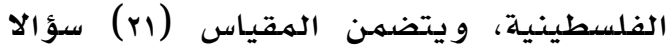
موزعة على خمسلة مواقف أخلاقية، اشتقت

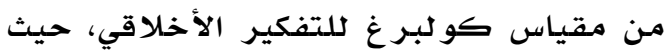
يتضمن كل موقف عددا من الأسئلة يلي كل سؤال (7) اختيارات يمثل كل اختيار مـرحلة من مـر احل التفكير الأخلاقي لدى كو لبرج،

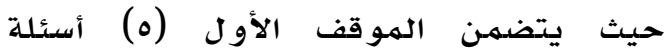
و الموقف الثاني (ه) أسئلة و المهوقف الثالث

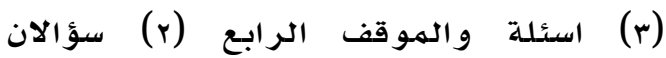

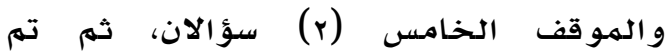

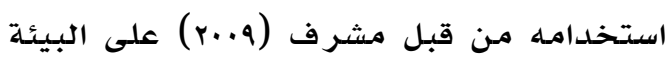
الفلسطينية في غزة، واستخرجت الده دله دلالات صدق المقارنة الطرفية كصدي كمق تمييز، حيث

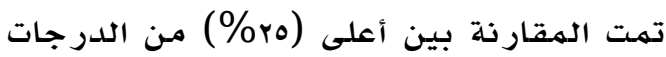

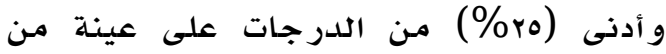

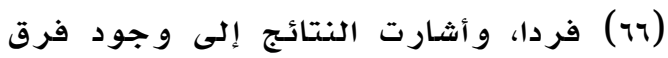

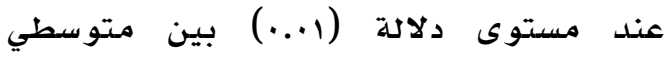
الفئتين العليا والدنيا، مها يشير إلى قدرة الهقياس على قياس الفروق الفردية لعينة

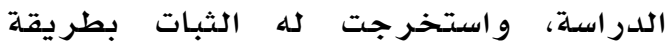
التجزئة النصفية و وريقة كرونباخ الفا، و لأغر اض الدراسـة الحالية تهم ما يلي:

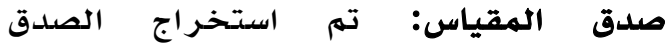

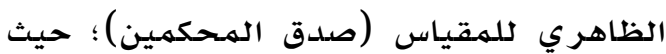


فيها سلوك الطفل الأخلاقي بناء على مبادئ

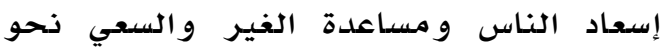
تقبلهم.

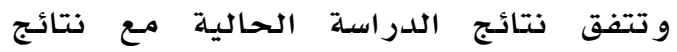

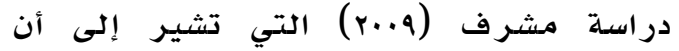

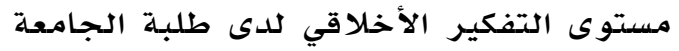

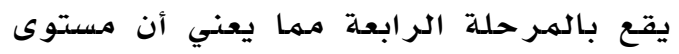

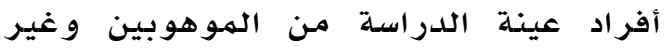

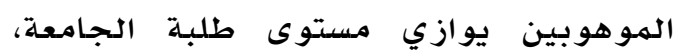
و تختلف مع دراسة شين يونغ و أولوزيسكي

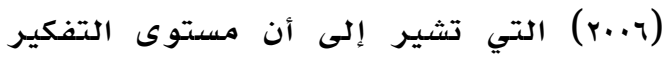

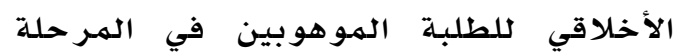

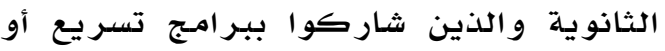

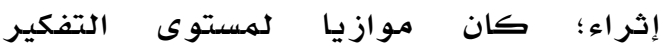

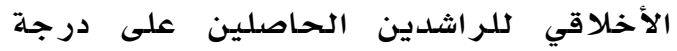
الماجستير • - المافي و ولإجابة عن سؤال الدراسة الثاني: هل توجد

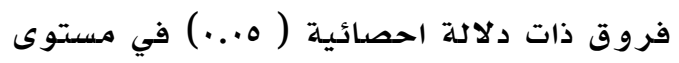

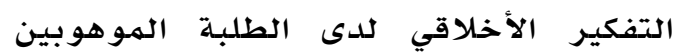

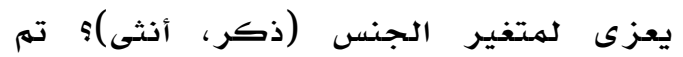

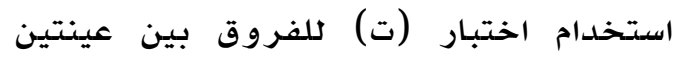

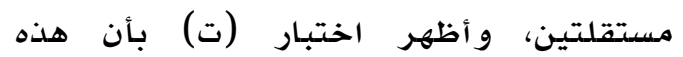

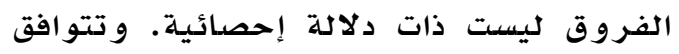
هذه النتيجة مـ الفرو نتائج دراسة دلات عباس (1990)

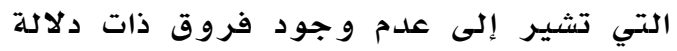

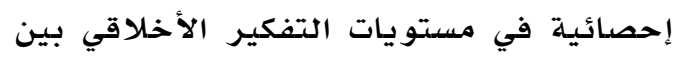
الذكور والإناث، وكذلك تتفق مـع دراسة

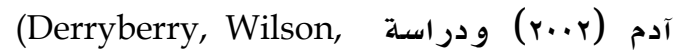
Snyder, Norman \& Barger, 2005)

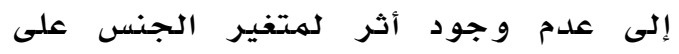

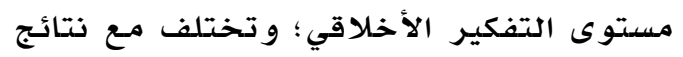

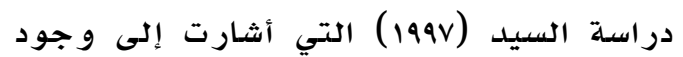
فروق في مستوى التفكير الأخلاقي بين إلى التودين الذكور والإناث لصالح الإناث.

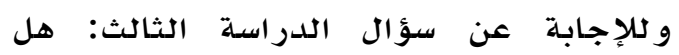

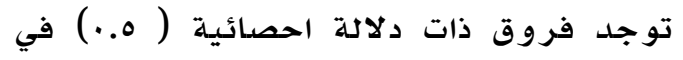

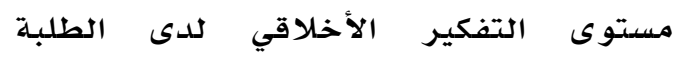

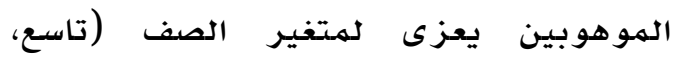
عاشر، أول ثاذوي)؟ تم استخدام تحليل
الزرقاء؟ تم مساب مجموع الدرجات

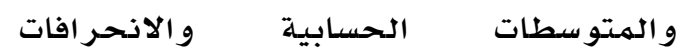
المعيارية لكل موقف من مواقف المقياس و جدو ل ه يبين ذلك.

- جدول

مستوى التفكير الأخلاقي على المواقف المختلفة للمقياس

\begin{tabular}{|c|c|c|c|c|}
\hline \multicolumn{2}{|c|}{ الانحراف المعياري } & \multicolumn{2}{|c|}{ المتوسط الحسابي } & \multirow{3}{*}{ الموقف } \\
\hline \multirow[t]{2}{*}{ الموهوبين } & غير & الموهوبين & غير & \\
\hline & الموهوبين & & الموهوبين & \\
\hline. .70 &.$\vee \vee \wedge$ & $r .79$ & $r .74$ & الأول \\
\hline . . & .01 & $\varepsilon \ldots$ & r.9. & الثاني \\
\hline.$\wedge \varepsilon$ & $1 . . r$ & $\varepsilon . .9$ & $r .97$ & الثالث \\
\hline $1 . r 4$ & 1.10 & $r .71$ & r.09 & الرابع \\
\hline . .9ז & $1 . . \varepsilon$ & $r . v \varepsilon$ & r.o. & الخامس \\
\hline \multirow[t]{2}{*}{..$\leqslant r$} &..$\leqslant r$ & r.M & r.VA & جميع \\
\hline & & & & المواقف \\
\hline
\end{tabular}

يعرض جدول • أن المتوسط الحسابي لمستوى التفكير الأخلاقي لدى طلبة عينة اندابل

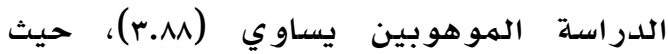

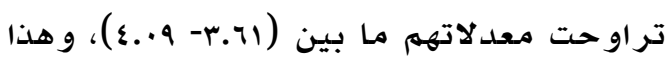

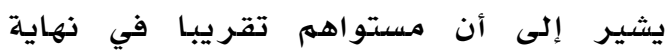

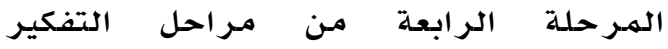
الأخلاقي؛ حيث ينظر الفرد إلى السلى السلوك

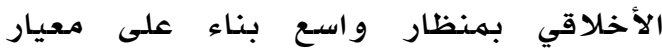
التمثل للقواعد والأنظمة التي تمثل السلطة

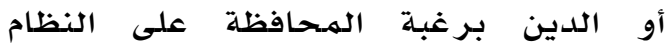

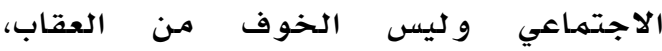
وانطلاقا من واجب الفرد الالتزام بها؛ أما

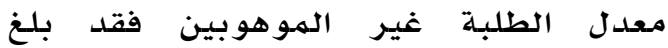
(r.vN)

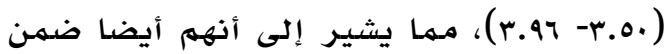

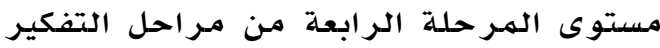
الأخلاقي لدى كو لبرغ غ. كما تم حساب المتوسطات الحسابية لكل الحرابل أفراد عينة الدراسة على كل سؤال من أسئلة المقياس حيث تبين أن بعض المتوسطات

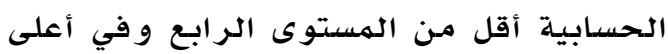

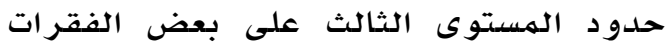

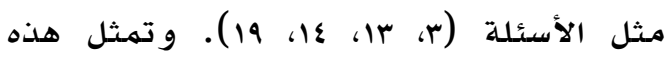
المرحلة أخلاق التعاون المشترك؛ ولان وينطلق 
تظهر أية فروق في المواقف جميعها بين

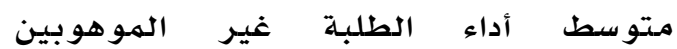

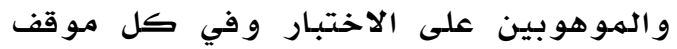

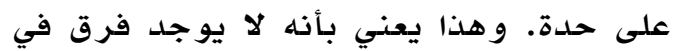
مستوى التفكير الأخلاقي بين الطلبة غير

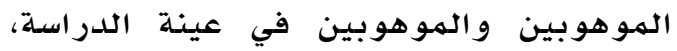

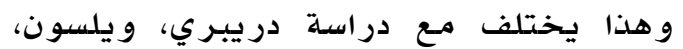

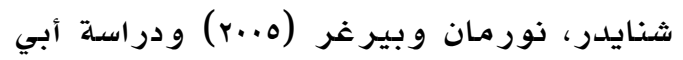

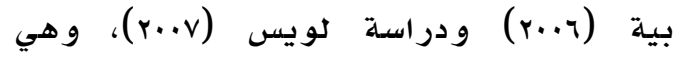
دراسات أشارت جميعها إلى وجود فروق بين

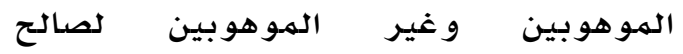

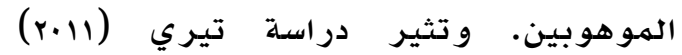

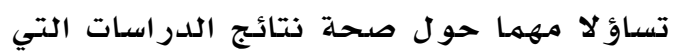
تشير إلى أن مستوى التفكير الأخلاقي للموهوبين أعلى من مستوى أقرانهم غير المير

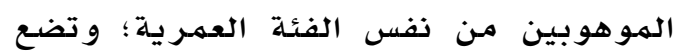

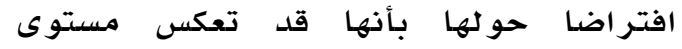

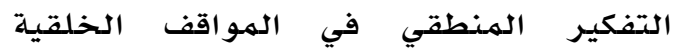

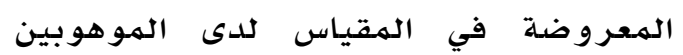
أكثر مها تعكس نمو تفكير هم الأخلاقي الحقيقي، وذلك بسبب قدرتهم على اختيار

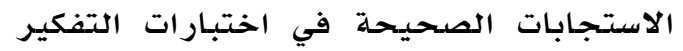
الأخلاقي.

و لإججابة عن السؤال الخامس: هل توجد فروق ذات دلادلة احصائية (ه...) في مستوى

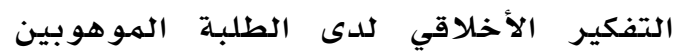

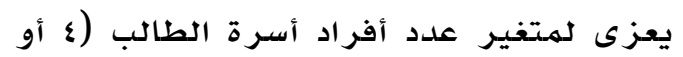

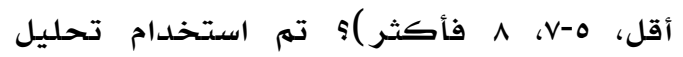
التباين الأحادي (one way ANOVA) لقياس الفروق في مستويات النهمو في التفكير التياي

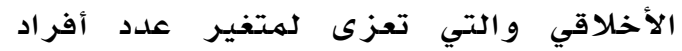

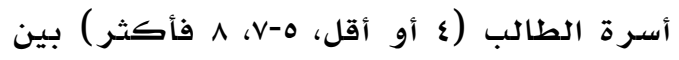

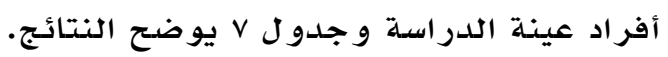

التباين الأحادي (one-way ANOVA) لقياس الفروق في مستويات النهمو في التفكير

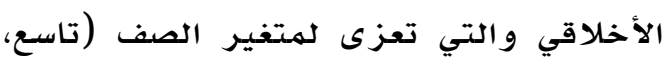

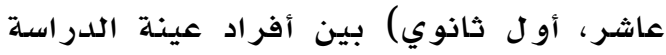

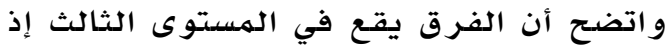

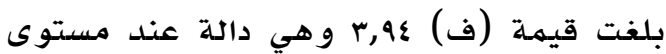

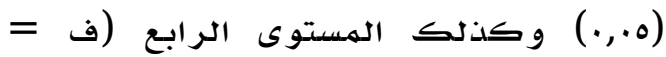

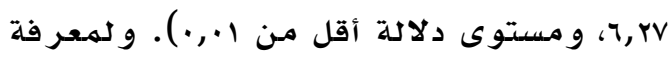
لصالح من الفروق التي ظهرت في الموقفين

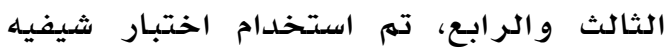

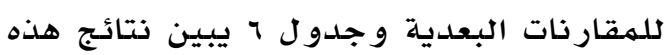
الهقار نات.

ويظهر جدول 1 بأن هناك فروقا ظاهرية بين الصفوف الثلاثة في الموقفين الثالث

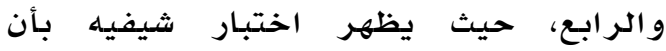

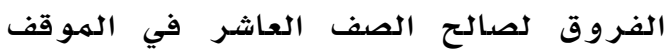

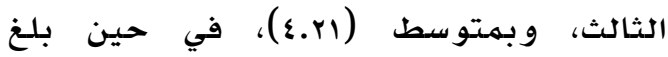

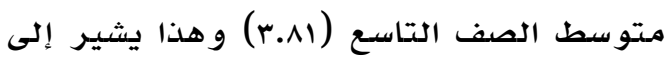
أن هنالك فروق في الأداء على الاختبـار لصالح الصف العاشر، كما يظهر بأن هنالك فروقا جوهرية بين الصف التاسع والأول

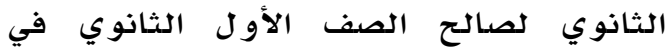
الموقف الر ابع • و تتتفق هذه النتيجة مـع نتائج دراسـة طوقان و أرناؤوط (1910) التي أشارت إلى وجود علاقة إيجابية ذات دلادة بلد بين مستويات النمو المعرفي ودمستوديات التفكير الأخلاقي. و وتتفق مع دراستة عبـاس (1990) التي أشارت إلى وجود فروق ذات ذاتل دلادلة إحصائية في مستوى التفكير الأخلاقي بين

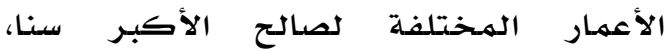

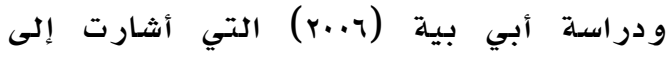

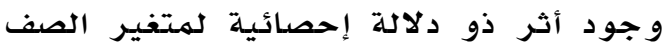
على مستوى التفكير الأخلاقي لصالح الصف دود إحله

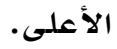

و كلإجابة عن سؤال الدراسة الرابع: هل توجد فروق ذات دلادلة احصائية (0.•) في

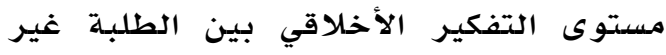
الهوهو بين و الهوهوبين؟ تم استخدام اختبـار (ت) للفروق بين عينتين مستقلتين، ولهم 


\section{جدول 1}

نتائج اختبار شيفيه للمقارنات البعدية

\begin{tabular}{|c|c|c|c|c|c|c|}
\hline اول ثانوي & عانر & ت تاسع & الصف & الوسط الحسابي & الصف & الموقف \\
\hline- & $* \ldots \leqslant \varepsilon$ & - & تاسع & $r . \wedge$ & تاسع & الثالث \\
\hline- & - & & عاشر & $1 \cdot \varepsilon . r_{1}$ & عاشر & \\
\hline- & - & & حادي عشر & $\mid I \varepsilon . r$ & حادي عشر & \\
\hline اول ثانوي & عاشر & ت تاسع & الصف & الوسط الحسابي & الصف & الرابع \\
\hline$\because \ldots 10$ & - & & تاسع & r.r. & تاسع & \\
\hline- & - & & عاشر & r.rr & عاشر & \\
\hline- & - & & اول ثانوي & £.11 & اول ثانوي & \\
\hline
\end{tabular}

جدول

نتائج تحليل التباين الأحادي لقياس الفروق في مستويات التفكير الأخلاقي لاى أفراد عينة الدراسة الموهوبين والتي تعزى لمتغير عدد أفراد أسرة

\begin{tabular}{|c|c|c|c|c|c|c|}
\hline \multirow[b]{2}{*}{ مستوى الدلالة } & \multicolumn{4}{|c|}{ الطالب } & \multirow[b]{2}{*}{ مصدر الثباين } & \multirow[b]{2}{*}{ الموقف } \\
\hline & قيمة ف & متوسط & درجة & مجموع المربعات & & \\
\hline \multirow{3}{*}{. .Ar. } & \multirow{3}{*}{. IAV } &. .117 & $r$ & ..rTI & بين المجموعات & \multirow{3}{*}{ الأول } \\
\hline & &. .719 & $11 \%$ & 79.97 & داخل المجموعات & \\
\hline & & - & 110 & $v . .191$ & المجموع & \\
\hline \multirow{3}{*}{$* \ldots 1$} & \multirow{3}{*}{ Y. $\{01$} & T.97\& & r & V.9YA & بين المجموعات & \multirow{3}{*}{ الثاني } \\
\hline & & . . Orr & $11 \pi$ & T...1T. & داخل الدجموعات & \\
\hline & & - & 110 & $\Upsilon \lambda . . \leq \wedge$ & المجموع & \\
\hline \multirow{3}{*}{. .VTr } & \multirow{3}{*}{ Tr } & . rro & r & $\therefore \leqslant 0$ & بين المجموعات & \multirow{3}{*}{ الثالث } \\
\hline & &..$V T$ & $11 \pi$ & אות & داخل المجموعات & \\
\hline & & - & 110 & AI.VAr & المجموع & \\
\hline \multirow{3}{*}{.. VTV } & \multirow{3}{*}{ דצד } & .. $\varepsilon \cdot r$ & r & $\cdot . \wedge \cdot \varepsilon$ & بين المجموعات & \multirow{3}{*}{ الرابع } \\
\hline & & 1.0 .1 & $11 \pi$ & iv..tVo & داخل الدجموعات & \\
\hline & & - & 110 & ivi.iva & المجموع & \\
\hline \multirow{3}{*}{$.0 \mathrm{Vy}$} & \multirow{3}{*}{$.00 \leqslant$} &..$\varepsilon \gamma_{0}$ & r &. .90 & بين المجموعات & \multirow{3}{*}{ الخامس } \\
\hline & & . Aov & $11 \pi$ & $97 . \vee 91$ & داخل الدجموعات & \\
\hline & & - & 110 & $9 \vee . \vee \leqslant \wedge$ & المجموع & \\
\hline \multirow{3}{*}{$* \ldots \varepsilon$} & \multirow{3}{*}{ O.VTr } & $. .9 \leqslant \wedge$ & r & 1.190 & بين المجموعات & \multirow{3}{*}{ جميع } \\
\hline & &. $.17 \varepsilon$ & $11 \%$ & $11.0 N r$ & داخل المجموعات & \\
\hline & & - & 110 & $r . . \Sigma v \wedge$ & المجموع & \\
\hline
\end{tabular}

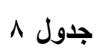

نتائج اختبار شيفيه للمقارنات البعدية لمتوسطات أداء الطلبة الموهوبين حسب متغير عدد أفراد الأسرة

\begin{tabular}{|c|c|c|c|c|c|c|}
\hline A أفراد فأكثر & V - أفراد & ع أفراد أو & عدد أفراد الأسرة & الحسابي & عدد أفراد الأسرة & الموقف \\
\hline$* \ldots 1$ & $* \ldots r$ & - & ع أفراد أو أقل & T.乏A & ؟ أفراد أو أقل & \\
\hline- & - & - & V - & r.qv & V - & الثناني \\
\hline-- & - & - & ^ أفراد فأكثر & 纟.। & ^ أفراد فأكثر & \\
\hline A أفراد فأكثر & V - أفراد & ع أفراد أو & عدد أفراد الأسرة & الوسابي & عدد أفراد الأسرة & الكلي \\
\hline$* \ldots \wedge$ & $* \ldots v$ & - & ع أفراد أو أقل & r.Ar & ع أفراد أو أقل & \\
\hline- & - & - & أفراد V - 0 & r.NI & أفراد V - & \\
\hline- & - & - & ^ أفراد فأكثر & r.91 & ^ أفراد فأكثر & \\
\hline
\end{tabular}


الولادي في أسرته، أي أنه لا يوجد أثر للمتغير على مستوى التفكير الخلقي. التوصيات

1. التخطيط لبر امج إرشادية للموهوبين

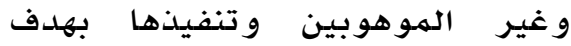
زيادة مستوى تفكيرهم الأخلاقي.

r. تضمين المناهج و البرامج التعليمية المختلفة موادا تهدف إلى تطوير

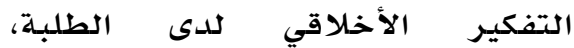

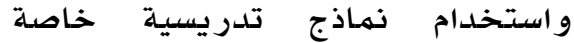

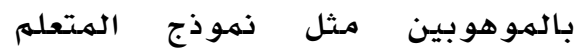

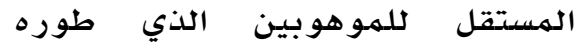

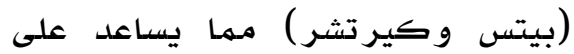
تطوير شخصياتهم ومستوى تحقيق ذو اتهم.

r. استخدام معايير و وجدانية لتصنيف

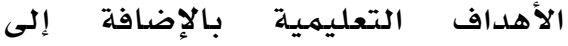
معايير التصنيف المعر فية المستخدمة و إجراء المزيد من الدراسات حول هذا لهائا الموضوع و باستخدام مقاييس أخرى

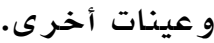

\section{المر اجع}

\section{References}

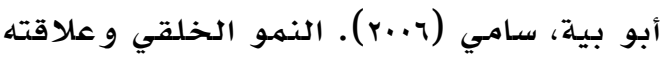

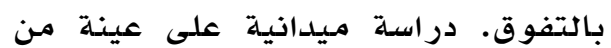
تلاميذ مدارس الرياض. كلية التربية،

جامعة المنصورة، المجلة العلمية، عا(ץ)، ט آدم، بسماء (Y...r). النمهو الأخلاقي و علاقته

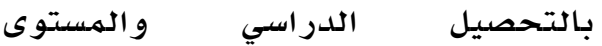
الاجتماعي الاقتصادي لأسرة. درواسة

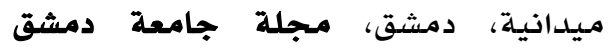

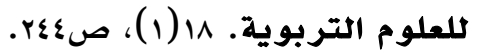

بروربا، ميشيل (r..r). بناء الذكاء الأخلاقي: المعايير والفضائل السبع التي تعلم الأطفال أن يكونوا اخلاقيين (طا).
وتظهر نتائج لتحليل التباين الأحادي للفروق في مستويات التفكير الأخلاقي لدى الدي الموهوبين والتي تعزى لمتغير عدد أفراد

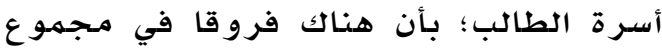

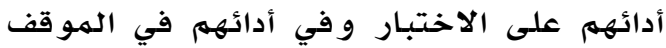

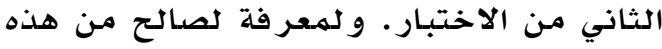
الفروق، تم استخدام اختبار شيفيه للمقار نات

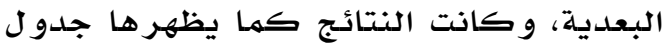
وتظهر نتائج جدول ^ للمقارنات البعدية لمتوسط أداء أفراد عينة الدراسلة الموهوبين على الموقف الثاني، وعلى الاختبار ككل، بأن هناك فروق جوهرية بين فئة الطلاب

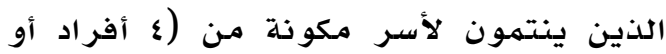

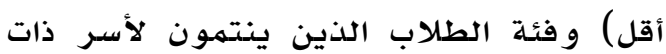
أفراد من ( وكذلك وجود فروق جوهرية بين فئة

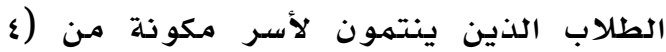
أفراد أو أقل) وبين فئة الطلاب الذين لابن الذين ينتمون لأسر تتكون من ^ أفراد فأكثر الفران

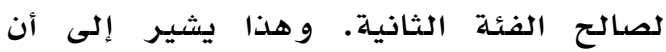

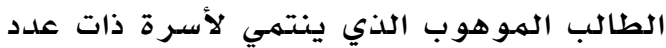
كبير أكثر نموا في مستوى التفكير الأخلاقي ؛ وقد تعود هذه النتيجة إلى اعتياد

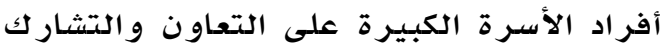
أكثر من أفراد الأسر الصغيرة. و للإجابة عن سؤال الدراسة السادس: هل

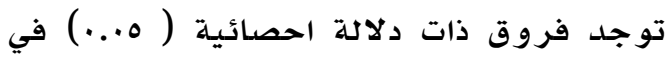

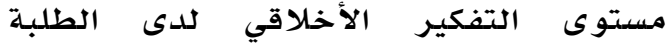

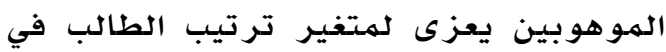
الأسرة (أكبر، أصغر، أوسط)؟ تم استخدام تحليل التباين الأحادي (one way ANOVA) لقياس الفروق في مستويات النمو في الادي التفكير الأخلاقي والتي تعزى لهتغير ترتيب

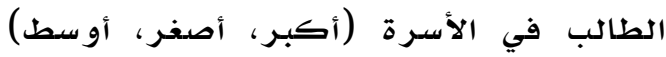
بين أفراد عينة الدراسة، ولك نظهلا نتائج

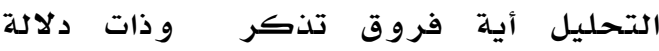
إحصائية في المستويات الأخلاقية للطلبة آلبة الموهوبين بناء على متغير ترتيب الطالب 
عدس، عبدالرحمن وتوق، محي الدين

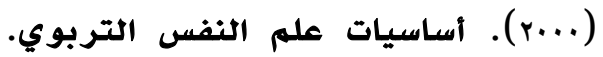
دار الفكر للنشر والتوزيع، عمان، النفاعيات

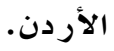

عدس، عبدالرحمن و وتوق، محي الدين

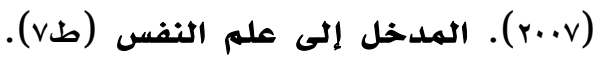

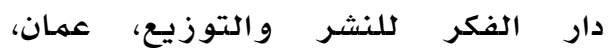

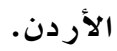

العزة، سعيد حسن (11) (1)). إرشاد الموهوبين والمتفوقين. عمان، دار الثقافة للنشر الثوهيد

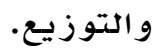

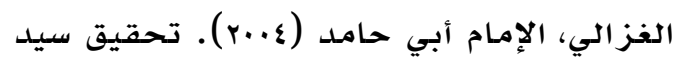

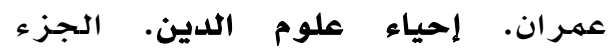
الثالث. دار الحديث، القاهرة.تأليف ليندا سيلفر مان كر يقر .

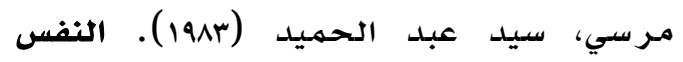
المطمئنة. دار التوفيق النهوذجية،

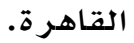

مشرف، ميسون (r.aq). التفكير الأخلاقي

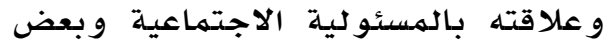
المتغير ات لدى طلبة الجامعة الاسلامية. رسالة ماجستير غير منشورة، الجامعة

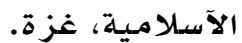

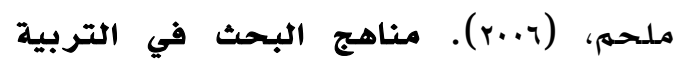

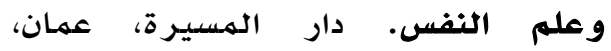

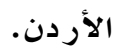

منسي، محمود (r.....). علم النفس النمو. مركز الاسكندرية للكتاب، الاسكندرية،

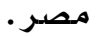

ناصر، إبراهيم (ج..r). التربية الأخلاقية. عمان، دار وائل للنشر.

Berk, L. E. (2003). Child development (6 $6^{\text {th }}$ ed). Boston Allyn and Bacon.

Derryberry, W. Pitt, Wilson, T., Snyder, H., Norman, T. \& Barger, B. (2005). Moral judgment developmental differences between gifted youth and college students. The Journal of Secondary Gifted Education. Vol. 17, No. 1, pp. 6-19.

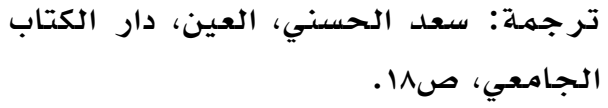

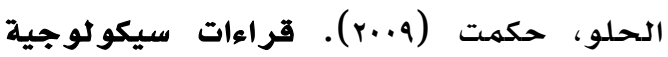

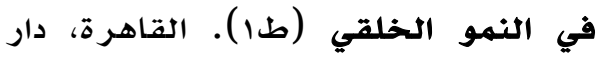
النشر للجامعات، النول

الريماوي، محمد عودة و آخرون (11.r). علم النفس العام (طء). عمان، دار المسيرة، ص

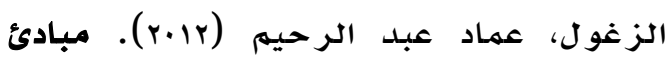
علم النفس التربوي (طr ). دار الكتاب

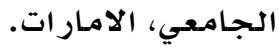

الزغول، عماد عبد الرحيم والهنداوي، علي

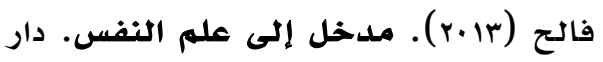
المسيرة للنشر و التوزيع، عمان، الأردن.

الزق، احمد يحيى (r.r). (ب). علم النفس مدخل

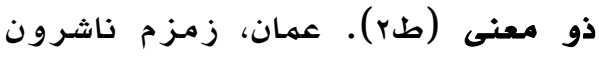
و موز عون.

السرور، ناديا (.1.r). مدخل إلى تربية

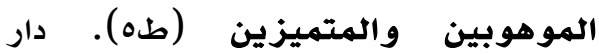
الفكر للنشر والتوزيع، عمان، الأردن.

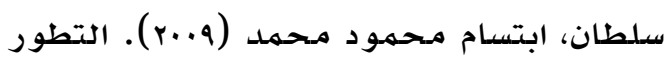
الخلقي للمراهقين. الأردن، عمان: دار صفاء للنشر و التوزيع. سليمان، علي السيد (......). نظريات التعلم

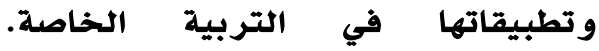
الرياض، مكتبة الصفحات الذهبية. السيد، نفين بكر عبد الرحمن محمدد (1999).

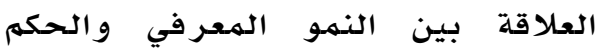

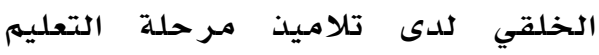
الأساسي. رسالة ماجستير غير منشورة.

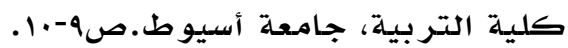
طوقان، محي الدين و أرناؤوط، سعادات

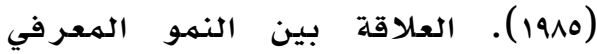

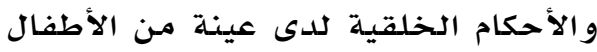

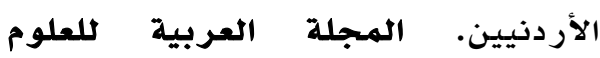
الانسانية، مجلس النشر العلمي، جامعة الاندية الكويت، العدد (1) الانسانية، مجل الثنا 
Gibbs, J. C., Basinger, K. S., Grime, R. L., \& Snarey, J. R. (2007). Moral judgment development across cultures: Revisiting Kohlberg's universality claims. Developmental Review, 27(4), 433-500. doi: 10.1016/j.dr.2007.04.001

http://www.moe.gov.jo/Departments/D epartmentsMenuDetails.aspx?MenuID $=697 \&$ DepartmentID $=30$

Karma, Y. (2014). The Indian model of moral development. Journal of Business Ethics. 123, 339-351.

Lewis, A. (2007). The moral judgment of gifted adolescents. University of Minnesota.

Seon-Y., Lee, P. (2006). The emotional intelligence, moral judgment, and leadership of academically gifted adolescents. Journal for the Education of the Gifted,30, p. 29.

Tirri, K. (2011). Combining excellence and ethics: implications for moral education for the gifted. Roeper Review, 33, 59-64. 